\title{
Performance of semirigid timber frame with Lagscrewbolt connections: experimental, analytical, and numerical model results
}

\author{
Takuro Mori $^{1} \cdot$ Makoto Nakatani $^{2} \cdot$ Solomon Tesfamariam $^{3}$
}

Received: 25 August 2015/ Accepted: 12 October 2015/Published online: 13 November 2015

(c) The Author(s) 2015. This article is published with open access at Springerlink.com

\begin{abstract}
This paper presents analytical and numerical models for semirigid timber frame with Lagscrewbolt (LSB) connections. A series of static and reverse cyclic experimental tests were carried out for different beam sizes $(400,500$, and $600 \mathrm{~mm}$ depth) and column-base connections with different numbers of $\operatorname{LSBs}(4,5,8)$. For the beam-column connections, with increase in beam depth, moment resistance and stiffness values increased, and ductility factor reduced. For the column-base connection, with increase in the number of LSBs, the strength, stiffness, and ductility values increased. A material model available in OpenSees, Pinching4 hysteretic model, was calibrated for all connection test results. Finally, analytical model of the portal frame was developed and compared with the experimental test results. Overall, there was good agreement with the experimental test results, and the Pinching4 hysteretic model can readily be used for full-scale structural model.
\end{abstract}

Solomon Tesfamariam

solomon.tesfamariam@ubc.ca

Takuro Mori

moritakuro@ rish.kyoto-u.ac.jp

Makoto Nakatani

nakatani-makoto@pref.miyazaki.lg.jp

1 Laboratory of Structural Function, Research Institute for Sustainable Humanosphere Kyoto University Gokashou, Uji, Kyoto 611-0011, Japan

2 Construction Development Division, Miayazaki Prefectural Wood Utilization Research Center, 21-2 Hanaguri, Miyakonojo, Miyazaki 885-0037, Japan

3 School of Engineering, The University of British Columbia, Okanagan Campus, 3333 University Way, Kelowna, BC V1V 1V7, Canada
Keywords Lagscrewbolt · Glulam timber - Connection · Semirigid portal frame Analytical model $\cdot$ Numerical model $\cdot$ Finite element model

\section{Introduction}

In Japan, there is a push to use timber in residential and non-residential buildings for consideration of sustainability. In October 2010, new legislation that promotes the use of wood in public buildings was enacted (Forestry Agency 2011). As Japan is located in high seismic zone, rigorous seismic design detailing and quality of construction are important considerations. Inoue et al. (1999) highlighted that, with the number of skilled carpenters decreasing, while meeting stringent performance requirement, connection detailing should be easy to construct. Various connection types are provided as a viable solution to be used in the timber industry, e.g., glued in rod (e.g., Tlustochowicz et al. 2011; Sato et al. 2007; Inoue et al. 1999), drift pins (e.g., Shojo et al. 2004, 2005).

The focus of this paper is on versatile connection detailing called Lagscrewbolt (Fig. 1, LSB) that was developed for semirigid connection (Komatsu et al. 1999). The LSBs have thread-like lagscrews on the outside surface and thread-like nut in the inside (Fig. 1). The LSBs were developed as a simple and economical fastener for moment-resisting joint of glulam timber (e.g., Fig. 2) (Mori et al. 2009; Nakatani et al. 2008; Komatsu et al. 1999). Nakatani et al. (2008) reported experimental and analytical models for LSBs used in beam-column joint. Figure 3 shows the application of LSB-based connectors in a glulam timber building. The connection details shown in Fig. 3 highlight that the LSBs are embedded within the 


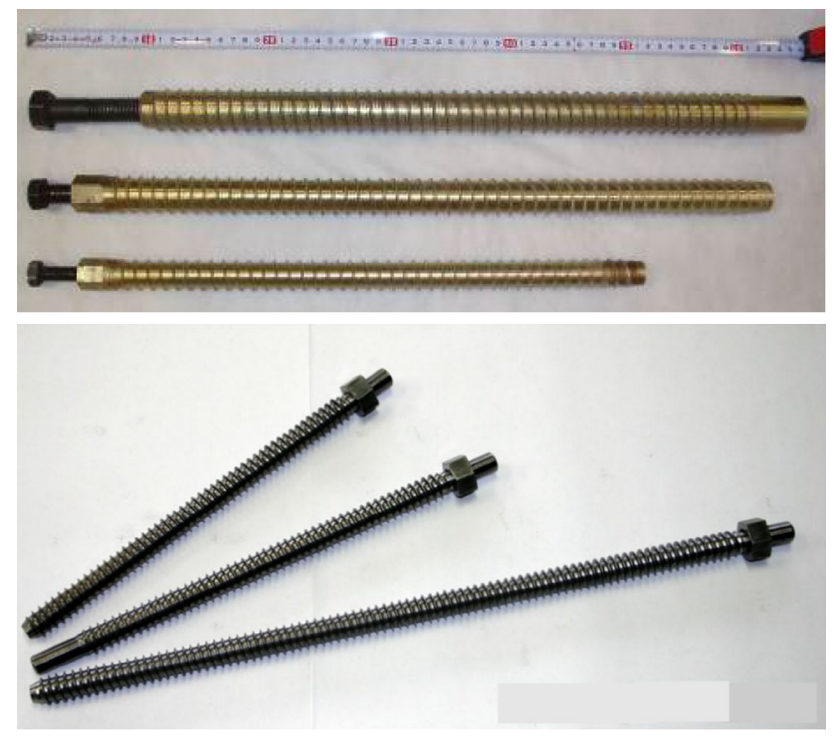

Fig. 1 Lagscrewbolts

glulam timber and can insulate the connection from fireinduced damage.

Nakatani and Komatsu (2005a, b, 2006) have developed analytical model for the pullout strength of LSBs in both parallel and perpendicular to grain direction (details are provided in the analytical model section). This paper extends this study to develop numerical model of the connections, and portal frame tested under monotonic and reverse cyclic test (Fig. 4). A series of static and reverse cyclic experimental tests were carried out for beam-column (Fig. 5, different beam sizes 400, 500, and $600 \mathrm{~mm}$ depth were considered) and column-base (Fig. 6, different numbers of LSBs, 4, 5, 8, were considered) connections.

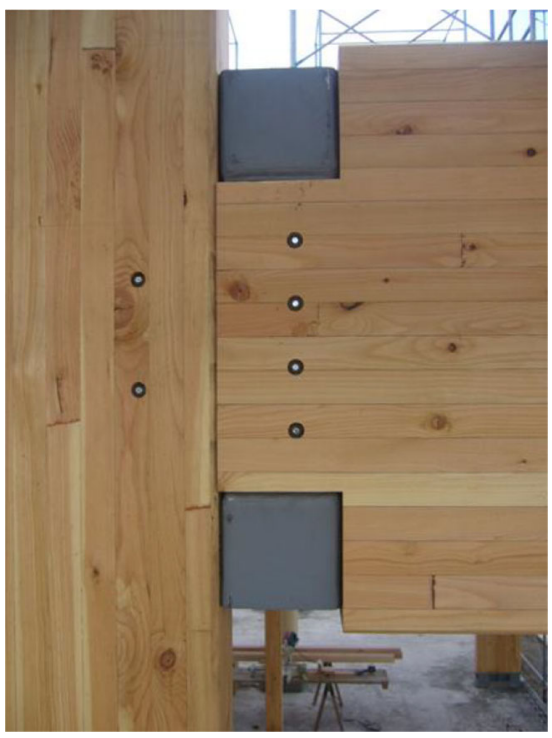

Fig. 2 LSB connections
The different beam sizes were considered, as the number of LSBs used varies. Three replicates of each connection and portal frame were considered. The monotonic and reverse cyclic load test results were used to calibrate numerical hysteretic model (Pinching4 hysteretic model, McKenna et al. 2000; Lowes et al. 2004). Open System for Earthquake Engineering Simulation (OpenSees, McKenna et al. 2000) finite element program was used to develop the analytical model of the connection and portal frame. The numerical model was developed to represent the cyclic energy dissipation capacity of the connection. To further investigate the utility of the calibrated Pinching4 hysteretic model, reverse cyclic loading test was carried out on a portal frame (Fig. 4), and the corresponding analytical and experimental load-deformation curve was compared.

\section{Experimental testing of connection and frame}

Test setups of the column-beam connection are shown in Fig. 5a, and connector details are shown in Fig. 5b. The tests were carried out at Kyoto University structural testing facility. Cyclic load was applied at a beam height of $2150 \mathrm{~mm}$. The beam depths considered were 400, 500, and $600 \mathrm{~mm}$, denoted as HTA400, HTA500, and HTA600, respectively. The connection details with corresponding LSB locations are shown in Fig. 5c. Specimen HTA400 had six LSBs with two connectors, whereas specimens HTA500 and HTA600 had nine LSBs with three connectors. Lengths of the LSBs used were 214 and $425 \mathrm{~mm}$, respectively, embedded in the column and beam. For the 400-mm beam width, two connectors at a spacing of $240 \mathrm{~mm}$ were used. For the $500-\mathrm{mm}$ and $600-\mathrm{mm}$ beam depths, three connectors were used at a spacing of 170 and $220 \mathrm{~mm}$, respectively.

A schematic and photograph of the test setups of the column-base connection are shown in Fig. 6a, b, respectively. For the column-base connection, the column was inserted into a 200-mm-high and 20-mm-thick steel sleeve. The LSBs were bolted to 20 -mm-thick steel plate that was welded to the steel sleeve. Depth of embedment of the LSBs in the column was $500 \mathrm{~mm}$. Three LSB arrangements and numbers were considered (Fig. 6c): 4, 5, and 8 LSBs are denoted as HCB4, HCB5, and HCB8, respectively. Cyclic load was applied at the column height of $2000 \mathrm{~mm}$.

Figure 7 shows the cyclic load used for the connection test. The loading was defined as story drift angle $(R)$, with $R$ values of $1 / 300,1 / 200,1 / 150,1 / 100,1 / 60,1 / 30(\mathrm{rad})$. After $R=1 / 30 \mathrm{rad}$, testing was continued with monotonic load to collapse. It should be noted that the testing cycles follow the Japanese standard loading criteria; however, instead of repeating the loading sequence three times, only 
Fig. 3 Glulam building with LSB connections (Cafeteria of Kinki University, Hiroshima Campus)

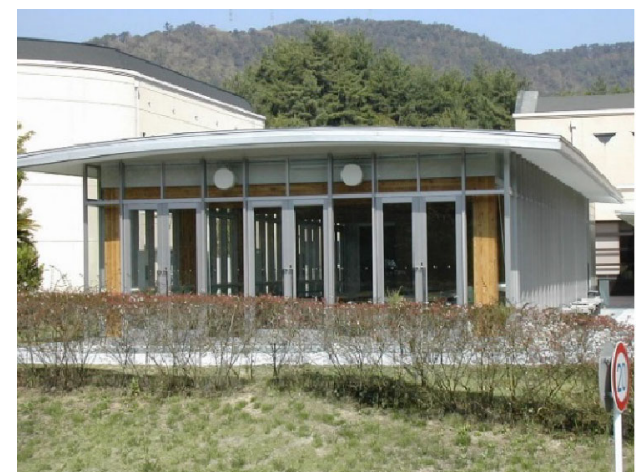

(a) Exterior of glulam building

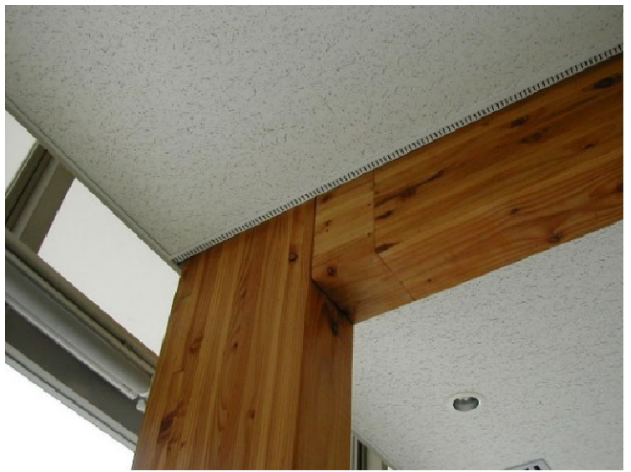

(c) Column-beam connection

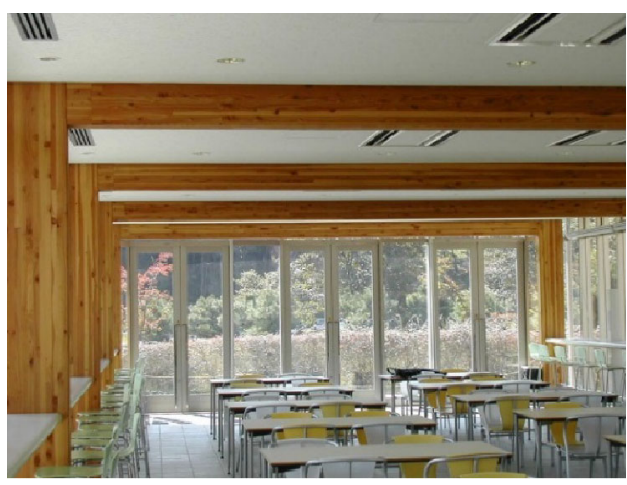

(b) Interior of glulam building

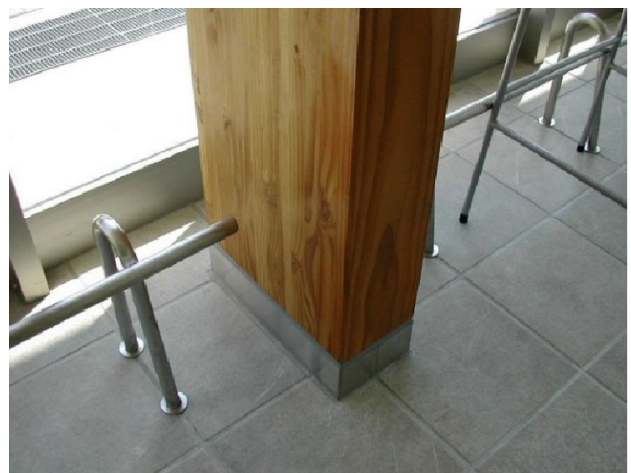

(d) Column-base connection one sequence is used. For this preliminary study of deriving analytical and numerical solutions, this simplification was sufficient. Further tests are indeed required with the proper loading sequence to generalize the model. The load was measured by the $200-\mathrm{kN}$ capacity load cell. Two LVDT sensors, placed on adjacent sides of the column-base (Fig. 5a), were used to monitor the joint rotation. Another LVDT, placed at the $2150 \mathrm{~mm}$ from the bottom, was used to measure the tip displacement.

\section{Analytical and numerical models}

Numerical and analytical models are developed to simulate the cyclic energy dissipation capacity of the connectors. Modeling of the connection can be achieved with complex continuum or simplified spring models (e.g., Lowes et al. 2004; Kouris et al. 2014; Nakatani and Komatsu 2005a, b, 2006). The hysteretic model considered can vary from a full characterization of the embedment properties of the bolts (e.g., Foschi 2000; Nakatani and Komatsu 2006) to macroscopic phenomenological approach of the connections (e.g., Rinaldin et al. 2013; Shen et al. 2013). In this paper, first, analytical models for the details of the LSB connections, derived in Nakatani and Komatsu (2005a, b, 2006), are provided. Rotational rigidity of both LSB

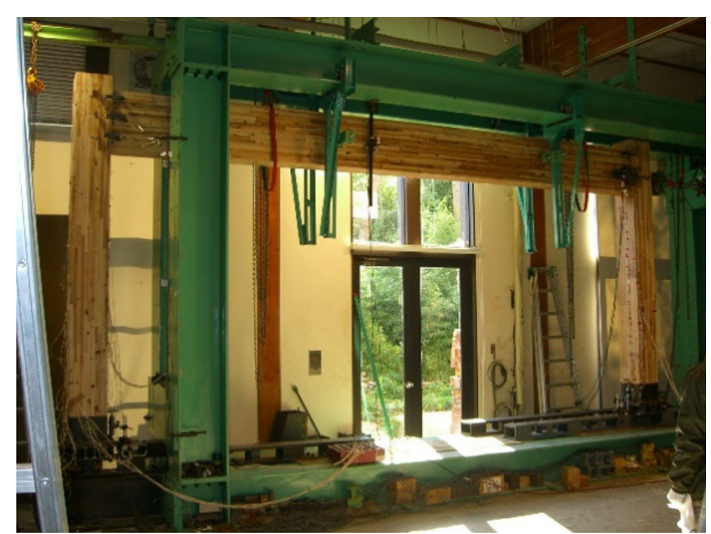

Fig. 4 Glulam portal frame

connections (Figs. 4, 5) was developed in Nakatani and Komatsu (2006). The analytical model for the strength of beam-column connection was developed in Nakatani et al. (2008). Details of the derivation are provided in the next section. In this paper, the analytical model for the columnbase connection is developed. The analytical models developed by Nakatani et al. (2008) compute rigidity and maximum strength, without accounting for the pinching and hysteretic response. Thus, a robust numerical model, Pinching4 hysteretic model (Lowes et al. 2004), was utilized to quantify the stiffness, strength at yield, cyclic 
Fig. 5 Details of beam-column connection: a schematic of test setup, b connector details, and c details of the beam-column connections (units are in $\mathrm{mm}$ )

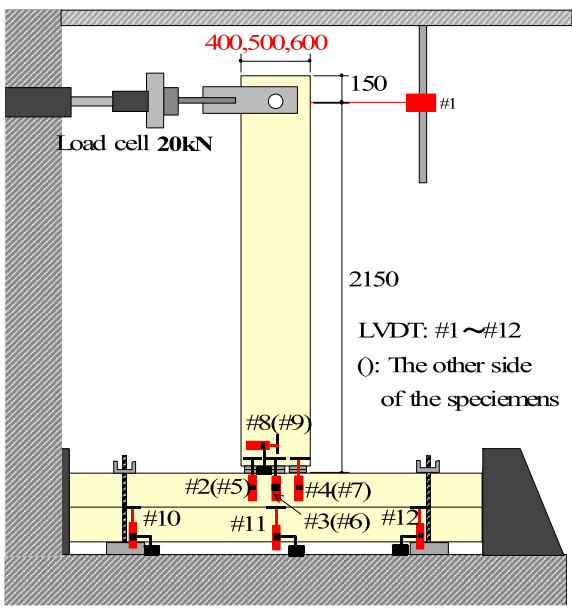

(a)

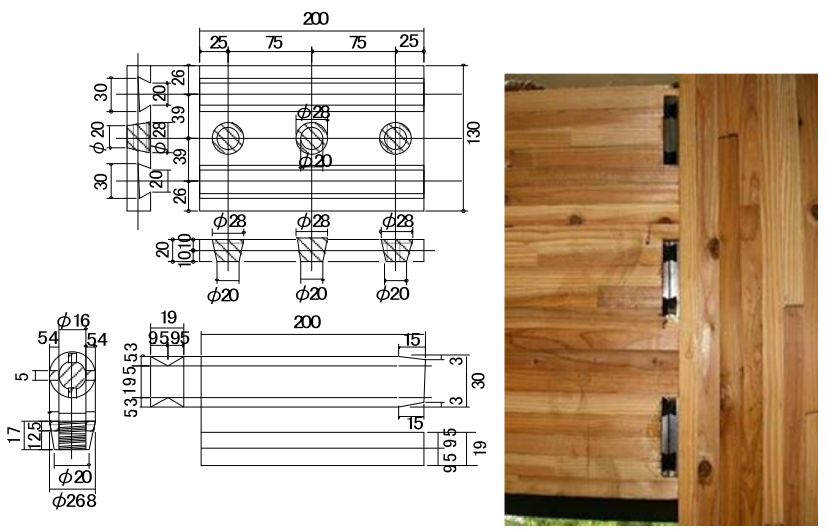

(b)

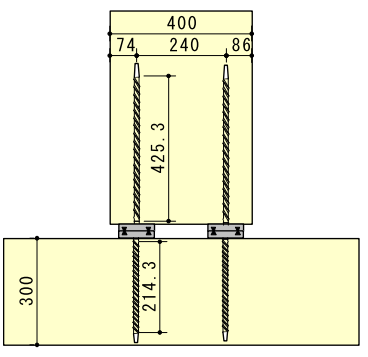

Beam depth: $400 \mathrm{~mm}$ (HTA400)

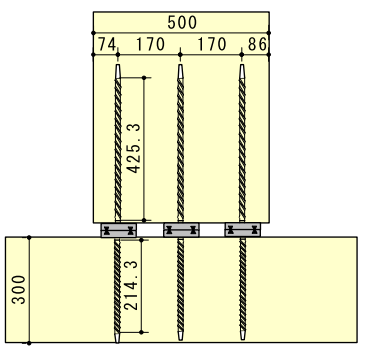

Beam depth: $500 \mathrm{~mm}$ (HTA500)

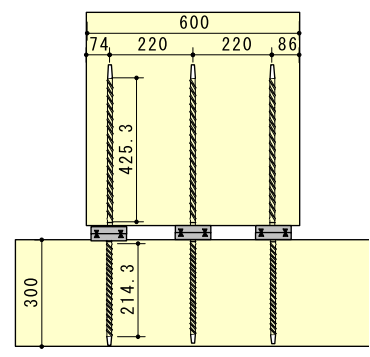

Beam depth: $600 \mathrm{~mm}$ (HTA600)

(c)

response, and pinching observed from the test results. The details are discussed below.

\section{Analytical model: beam-column connection}

In this section, the analytical model of the beam-column connection in the elastic range is presented. Schematics of the force at the beam-column connection and spring model representation, respectively, are shown in Figs. 8 and 9.
Figure 8 shows that, by applying negative moment $(M)$ at the connection, the LSBs located in the lower and upper sides of the connection are subject to tensile $(T)$ and compression $(C)$ forces, respectively. The $T$ is computed as a function of tensile semirigidity $k_{T}$ and can be obtained from the deformation geometry shown in Figs. 8 and 9 as (Nakatani et al. 2008):

$T=k_{T}(g-\lambda) \theta$ 
Fig. 6 Details of column-base connection: a schematic of test setup, $\mathbf{b}$ photograph of test setup, and $\mathbf{c}$ details of the column-base connections (units are in $\mathrm{mm}$ )

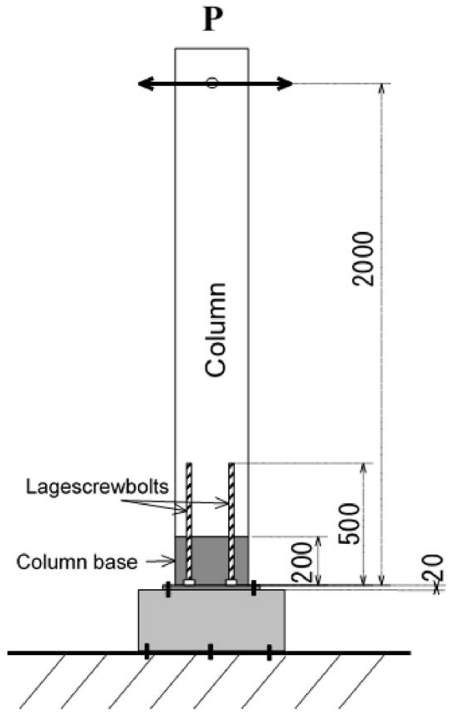

(a)

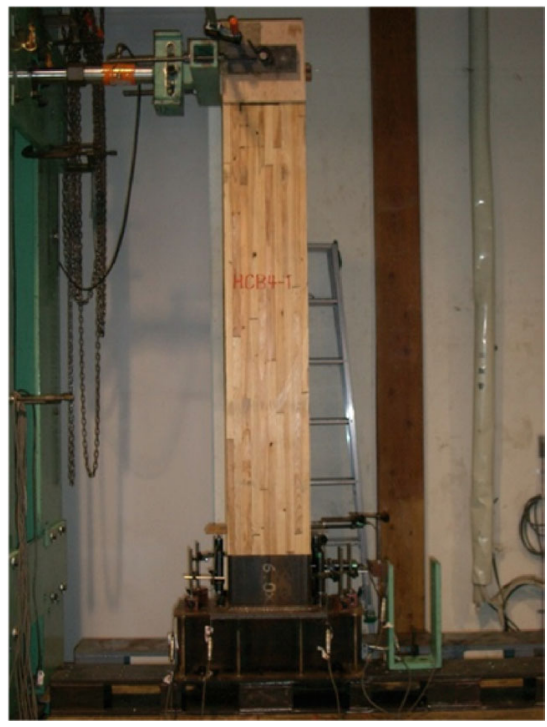

(b)

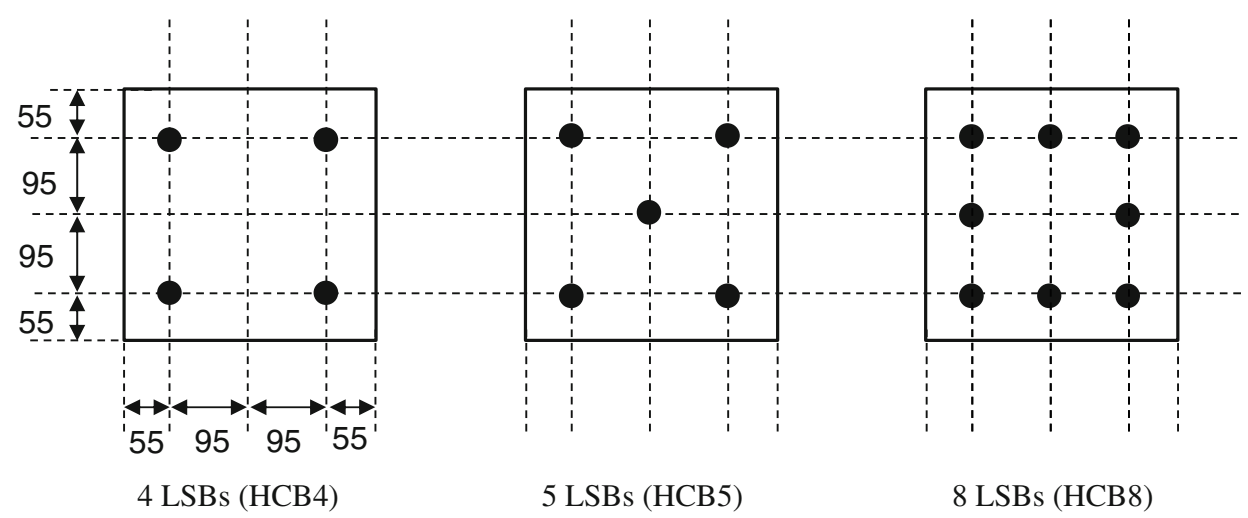

(c)

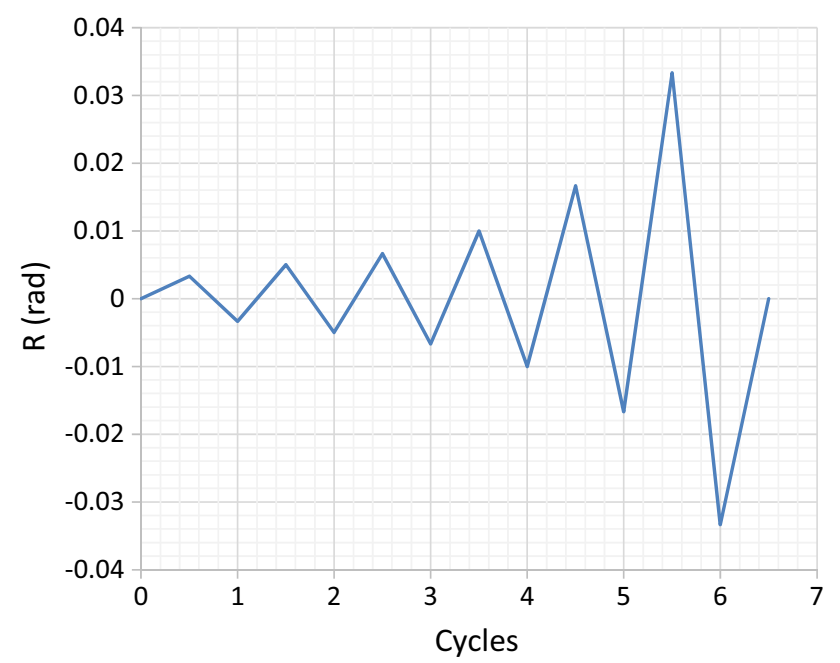

$k_{T}=\frac{k s_{\perp} k_{P T} k s_{\text {II }}}{k s_{\perp} k_{P T}+k s_{\perp} k s_{\text {II }}+k_{P T} k s_{\text {II }}}$

where $\theta$ is the rotation (rad); $k s_{\perp}$ and $k s_{\text {II }}$ are LSB slip modulus perpendicular and parallel to the grain $(\mathrm{N} / \mathrm{mm})$, respectively; $k_{P T}$ is tensile semirigidity of special connecters; $g$ is distance from lower edge to the upper LSB $(\mathrm{mm})$; and $\lambda$ is distance from lower edge to the neutral axis (mm). Theoretical slip moduli $\left(k s_{\perp}\right.$ and $\left.k s_{\text {II }}\right)$ were developed based on the Volkersen theory (Volkersen 1938) and are shown to be (Nakatani and Komatsu 2005a, b):

$k s= \begin{cases}\frac{\Gamma \pi R\left(E_{\mathrm{w}} A_{\mathrm{w}}+E_{\mathrm{s}} A_{\mathrm{s}}\right) \sinh k l}{k\left(E_{\mathrm{s}} A_{\mathrm{s}} \cosh k l+E_{\mathrm{w}} A_{\mathrm{w}}\right)} & \left(E_{\mathrm{w}} A_{\mathrm{w}} \leq E_{\mathrm{s}} A_{\mathrm{s}}\right) \\ \frac{\Gamma \pi R\left(E_{\mathrm{w}} A_{\mathrm{w}}+E_{s} A_{s}\right) \sinh k l}{k\left(E_{\mathrm{w}} A_{\mathrm{w}} \cosh k l+E_{\mathrm{s}} A_{\mathrm{s}}\right)} & \left(E_{\mathrm{s}} A_{\mathrm{s}} \leq E_{\mathrm{w}} A_{\mathrm{w}}\right)\end{cases}$

Fig. 7 Loading protocol 


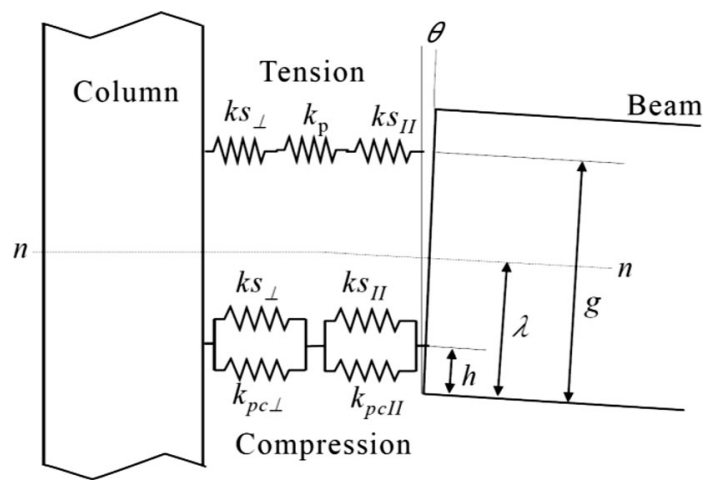

Fig. 9 Spring model of beam-column connection

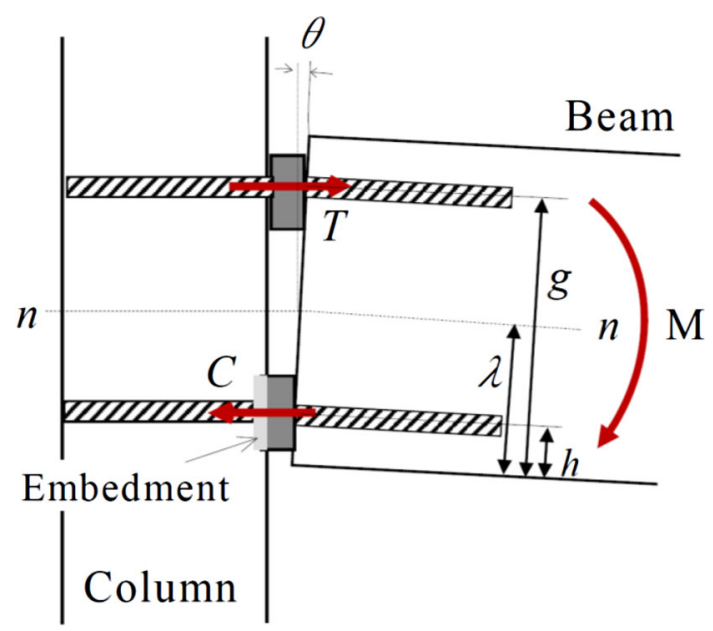

Fig. 8 Geometry of rotational semirigidity on beam-column connection

where $\Gamma$ is the shear stiffness of LSB connector which is defined as the ratio of shear stress to displacement $(\mathrm{N} /$ $\left.\mathrm{mm}^{3}\right) . R$ is the outer diameter of an LSB $(\mathrm{mm}) ; E_{\mathrm{w}}$ is modulus of elasticity of a glulam timber $\left(\mathrm{kN} / \mathrm{mm}^{2}\right) ; A_{\mathrm{w}}$ is effective area of glulam timber that resists pullout force of LSB $(2 \mathrm{R})\left(\mathrm{mm}^{2}\right) ; E_{\mathrm{s}}$ is modulus of elasticity of steel $(\mathrm{kN} /$ $\left.\mathrm{mm}^{2}\right) ; A_{\mathrm{S}}$ is the cross-sectional area of an LSB based on the minor diameter $\left(\mathrm{mm}^{2}\right)$; and $l$ is the effective inserted length of a LSB (mm). $k$ is a constant and is computed as:

$k=\sqrt{\Gamma \pi R\left(\frac{1}{E_{\mathrm{w}} A_{\mathrm{w}}}+\frac{1}{E_{\mathrm{s}} A_{\mathrm{s}}}\right)}$

The $A_{\mathrm{w}}$ of beam's LSBs (perpendicular to the grain, Eq. 5) and $A_{\mathrm{w}}$ of column's LSBs (parallel to the grain, Eq. 6) are computed as:

$A_{\mathrm{w}}=(4 R)(n R)-\pi\left(\frac{R}{2}\right)^{2}$ $n=2.683 e^{(3.591 / 3.591 h . h)}$

$A_{\mathrm{w}}=(4 R)(n R)-\pi\left(\frac{R}{2}\right)^{2}$

The $C$ is computed as a function of compression semirigidity $k_{C}$ and can be derived from the geometry shown in Figs. 8 and 9 as (Nakatani et al. 2008):

$C=k_{C}(\lambda-h) \theta$

$k_{C}=\frac{k s_{\perp} k_{p c \perp}}{k s_{\perp}+k_{p c \perp}}+\frac{k s_{I I} k_{p c I I}}{k s_{I I}+k_{p c I I}}$

where $h$ is the distance from lower edge to lower LSB in compression (mm), $k_{p c \perp}$ and $k_{p c \text { II }}$ are embedment semirigidity between steel plate and glulam perpendicular and parallel to the grain, respectively. From the equilibrium condition, $T=C$,

$k_{T}(g-\lambda)=k_{T} k_{C}(\lambda-h)$

Thus, location of neutral axis $\lambda$ is computed as:

$\lambda=\frac{k_{T} g+k_{C} h}{k_{T}+k_{C}}$

In the $T=C$ equilibrium condition, the axial force is neglected. From equilibrium forces of $T$ and $C$, the resultant moment $M$ at $\lambda$ is computed as

$M=\left[k_{T}(g-\lambda)^{2}+k_{C}(\lambda-h)^{2}\right] \theta$

Thus, rotational semirigidity $R_{\mathrm{JC}}$ of the beam-column connection is

$R_{\mathrm{JC}}=k_{T}(g-\lambda)^{2}+k_{C}(\lambda-h)^{2}$

Maximum moment $\left(M_{\max }\right)$ of the connection is assumed to be governed by minimum tensile strength $\left(P_{\mathrm{Tmax}}\right)$. The $P_{\text {Tmax }}$ is governed by the minimum pullout strength of LSB embedded in the column $\left(P_{\mathrm{LSBmax}}\right)$, and tensile strength of the special connectors $\left(P_{\mathrm{ptmax}}\right)$ is computed as:

$P_{\text {Tmax }}=\min \left\{\begin{array}{l}P_{\mathrm{LSBmax}} \\ P_{\mathrm{ptmax}}\end{array}\right.$

Theoretical $P_{\mathrm{LSBmax}}$ of LSB is computed as (Nakatani and Komatsu 2005a, b):

$P_{\mathrm{LSBmax}}= \begin{cases}\frac{f_{\mathrm{v}} \pi R\left(E_{\mathrm{w}} A_{\mathrm{w}}+E_{\mathrm{s}} A_{\mathrm{s}}\right) \sinh k l}{k\left(E_{\mathrm{s}} A_{\mathrm{s}} \cosh k l+E_{\mathrm{w}} A_{\mathrm{w}}\right)} & \left(E_{\mathrm{w}} A_{\mathrm{w}} \leq E_{\mathrm{s}} A_{\mathrm{s}}\right) \\ \frac{f_{\mathrm{v}} \pi R\left(E_{\mathrm{w}} A_{\mathrm{w}}+E_{\mathrm{s}} A_{\mathrm{s}}\right) \sinh k l}{k\left(E_{\mathrm{w}} A_{\mathrm{w}} \cosh k l+E_{\mathrm{s}} A_{\mathrm{s}}\right)} & \left(E_{\mathrm{s}} A_{\mathrm{s}} \leq E_{\mathrm{w}} A_{\mathrm{w}}\right)\end{cases}$

where $f_{v}$ is the shear strength $\left(\mathrm{N} / \mathrm{mm}^{2}\right)$ of an LSB joint which is defined as the shear force divided by the effective area. Thus, $M_{\max }$ is computed as: 


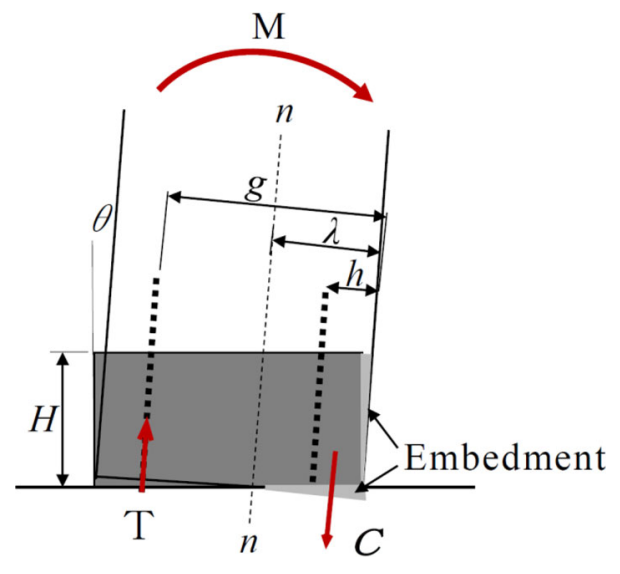

Fig. 10 Geometry of rotational semirigidity on column-base connection

$M_{\max }=\left(k_{T}(g-\lambda)^{2}+k_{C}(\lambda-h)^{2}\right) \frac{P_{\mathrm{T} \max }}{k_{T}(g-\lambda) .}$

\section{Analytical model: column-base connection}

Schematics of the force at the column-base connection and spring model representation, respectively, are shown in Figs. 10 and 11 . To simplify the model, in the preliminary derivation of the analytical model, effect of shear force was neglected in deriving the column-base connections. This should be considered in future extension of the model.

By applying a rotational angle $\theta$, the corresponding tensile force $T$ and compression force $C$ are shown in Fig. 10. The tensile force $T$ is computed as in Eq. 1, and corresponding total tensile semirigidity $k_{T}$ of the columnbase connection is computed as:

$k_{T}=\frac{k s_{\text {II }} k_{p n}}{k s_{\text {II }}+k_{p n}}$

where $k_{p n}$ is tensile semirigidity between special nut and steel box. The $k_{p n}$ is obtained from tensile test results of steel plate and special nut

Total compression force $C$ is computed as:

$C=C_{\mathrm{L}}+C_{\mathrm{W}}+C_{\mathrm{CL}}$

where $C_{\mathrm{L}}$ is compression force of $\mathrm{LSB}, C_{\mathrm{W}}$ is compression force between the steel box and column parallel to the grain, and $C_{\mathrm{CL}}$ is compression force between the steel box and column perpendicular to the grain. The $C_{\mathrm{L}}, C_{\mathrm{W}}$, and $C_{\mathrm{CL}}$ are computed as:

$C_{\mathrm{L}}=k s_{\mathrm{II}}(\lambda-h) \theta$

$C_{\mathrm{W}}=b \int_{0}^{\lambda} x \frac{k_{\mathrm{II}} \lambda \theta}{\lambda} d x=\frac{b k_{\mathrm{II}} \lambda^{2}}{2} \theta$

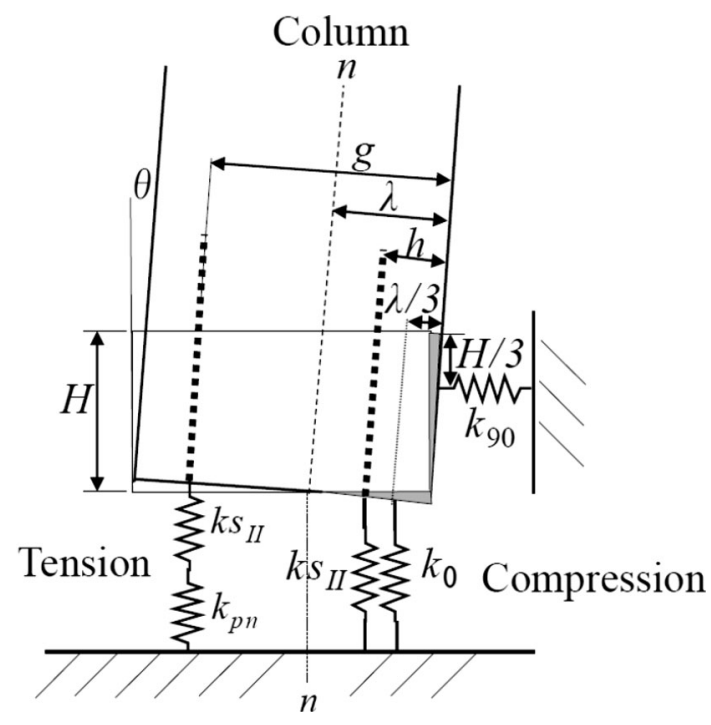

Fig. 11 Spring model of column-base connection

$C_{\mathrm{CL}}=b \int_{0}^{H} x \frac{k_{\perp} H \theta}{H} d x=\frac{b k_{\perp} H^{2}}{2} \theta$

where $b$ is column width $(\mathrm{mm}), k_{\mathrm{II}}$ and $k_{\perp}$ are embedment semirigidity parallel and perpendicular to the grain direction, and $H$ is height of steel box (mm). Neglecting the axial force component, from the equilibrium condition $T=C$, total tensile semirigidity $k_{T}$ is computed as:

$k_{T}(g-\lambda)=k s_{\mathrm{II}}(\lambda-h)+\frac{b k_{\mathrm{II}} \lambda^{2}}{2}+\frac{b k_{\perp} H^{2}}{2}$

Thus, location of neutral axis $\lambda$ is computed to be:

$$
\begin{aligned}
\lambda= & \frac{i}{b E_{0}}\left\{-\left(k_{T}+k s_{\mathrm{II}}\right)\right. \\
& \left. \pm \sqrt{\left(k_{T}+k s_{\mathrm{II}}\right)^{2}-2 b E_{0}\left(\frac{b E_{\perp} H^{2}}{2}-g k_{T}-h k s_{\mathrm{II}}\right)}\right\}
\end{aligned}
$$

Moment $M$ at $\lambda$ due to $T$ and $C$ is

$M=k_{T}(g-\lambda)^{2} \theta+k s_{\mathrm{II}}(\lambda-h)^{2} \theta+\frac{2 \lambda}{3} C_{\mathrm{w}}+\frac{2 H}{3} C_{\mathrm{CL}}$

Thus, the rotational semirigidity $R_{J B}$ is

$R_{J B}=k_{T}(g-\lambda)^{2}+k s_{\mathrm{II}}(\lambda-h)^{2}+\frac{b k_{\mathrm{II}} \lambda^{3}}{3}+\frac{b k_{\perp} H^{3}}{3}$

The $M_{\max }$ is assumed to be governed by $P_{\text {Tmax }}$ (shown in Eq. 13). Thus, $M_{\max }$ is 


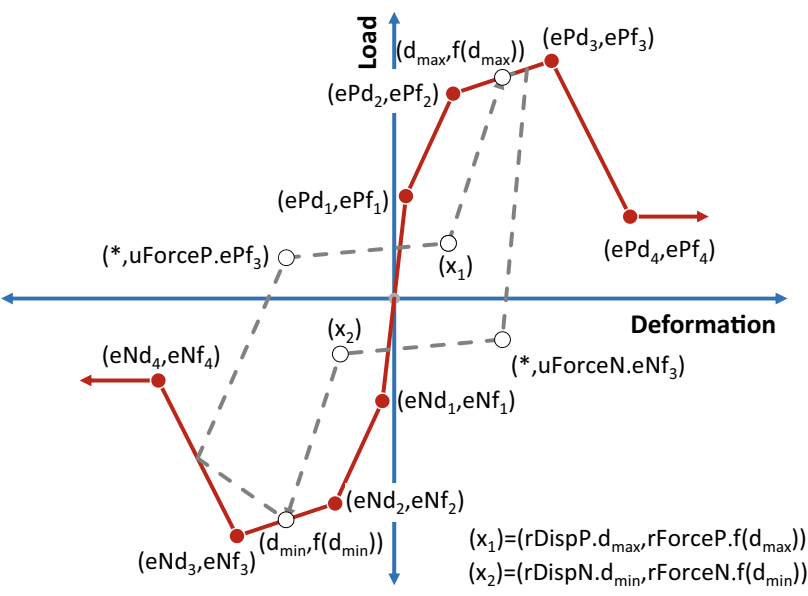

Fig. 12 Pinching4 hysteretic model (source: OpenSees Wiki http:// opensees.berkeley.edu/wiki/index.php/Pinching4_Material)

$$
\begin{aligned}
M_{\max }= & \left(k_{T}(g-\lambda)^{2}+k s_{\mathrm{II}}(\lambda-h)^{2}\right. \\
& \left.+\frac{b k_{\mathrm{II}} \lambda^{3}}{3}+\frac{b k_{\perp} H^{3}}{3}\right) \frac{P_{\operatorname{Tmax}}}{k_{T}(g-\lambda)}
\end{aligned}
$$

\section{Pinching4 hysteretic model}

To model the different connection test results and portal frame, an Open System for Earthquake Engineering Simulation (OpenSees) (Mckenna et al. 2000) finite element program was utilized. The nonlinear hysteretic response of the connections in OpenSees was modeled with a 16-parameter Pinching 4 hysteretic model (Fig. 12; Lowes et al. 2004). This model is composed of piecewise linear curves that represents a "pinched" load-deformation response and accounts for
Fig. 13 Damage observed response of the three beamcolumn connections

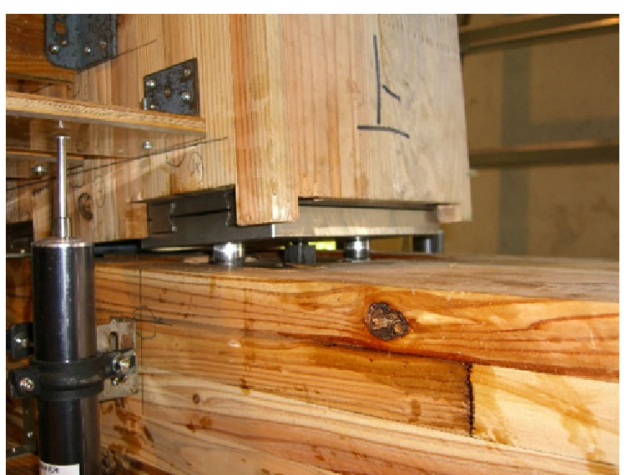

(a) HTA400

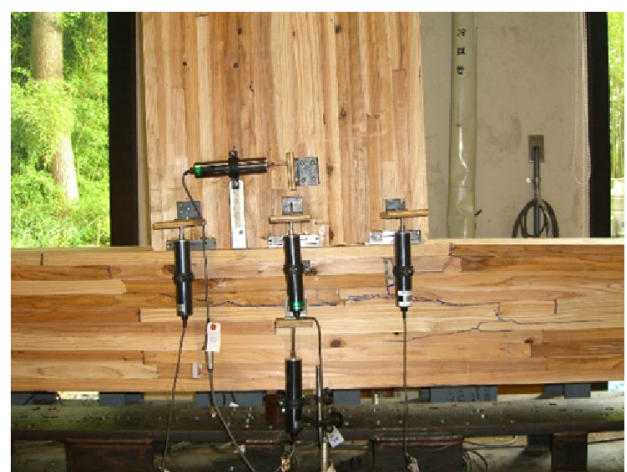

(b) HTA600-1

Fig. 14 Damage observed on the column-base connections
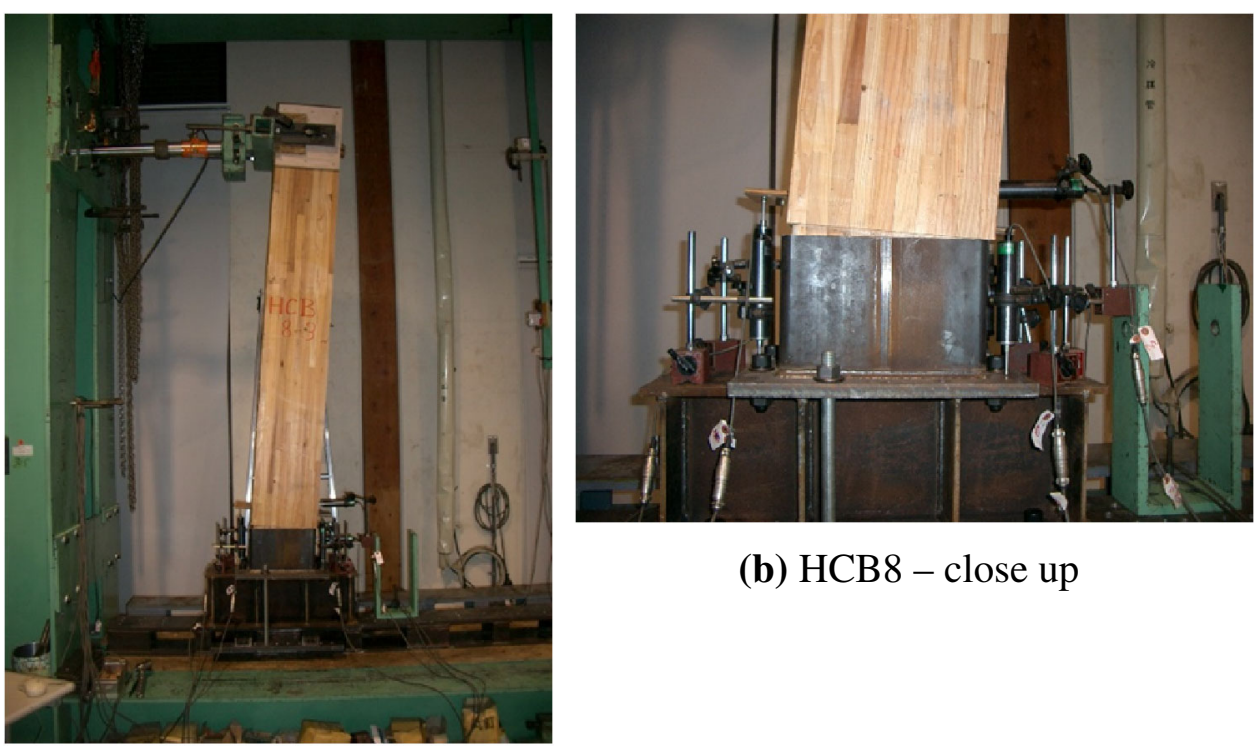

(b) HCB8 - close up

(a) $\mathrm{HCB} 4$ 

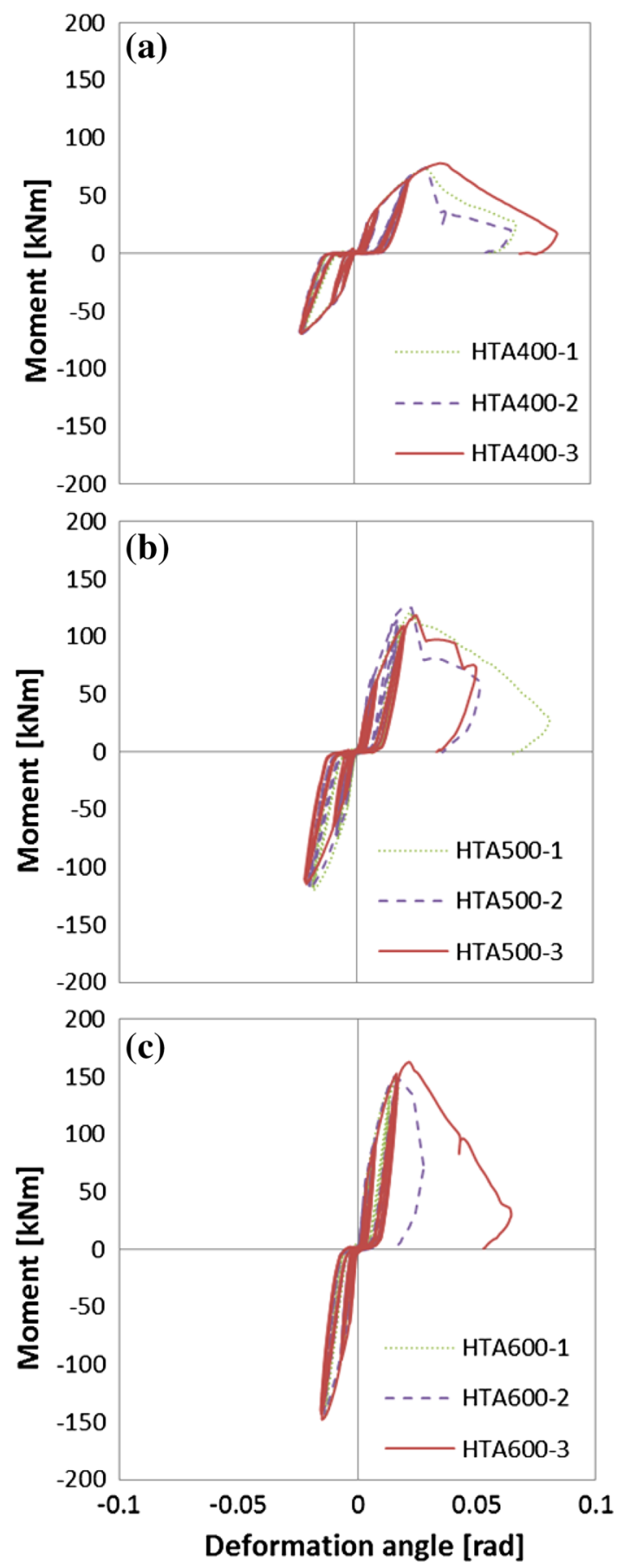

Fig. 15 Hysteretic response of the beam-column connections a HTA400, b HTA500, and c HTA600

stiffness and strength degradation under cyclic loading. The Pinching4 hysteretic model was first developed by Lowes et al. (2004) to model RC beam-column joint, and it is suitable for two-dimensional structures. Shen et al. (2013) have reported the use of the Pinching4 hysteretic model in a crosslaminated timber-steel connector brackets. Rahmanishamsi et al. (2015) have used the Pinching4 hysteretic model for gypsum board to steel stud connection.
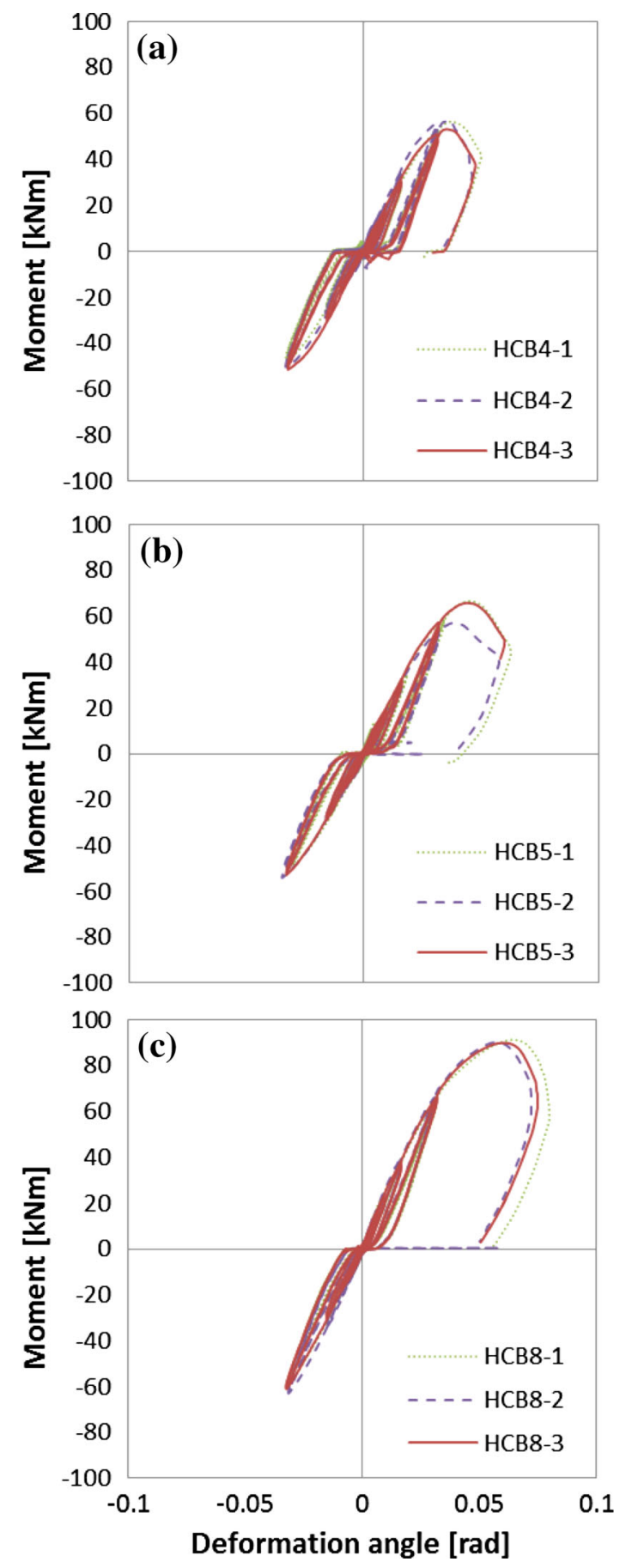

Fig. 16 Hysteric response of the semirigid column-base connections a $\mathrm{HCB} 4$, b HCB5, and c HCB8

The 16-parameter piecewise linear curves (Fig. 8) are used to define the positive $\left[\left(\mathrm{ePd}_{1}, \mathrm{ePf}\right)_{1}\right),\left(\mathrm{ePd}_{2}, \mathrm{ePf}_{2}\right)$, $\left.\left(\mathrm{ePd}_{3}, \mathrm{ePf}_{3}\right),\left(\mathrm{ePd}_{4}, \mathrm{ePf} \mathrm{P}_{4}\right)\right]$ and negative $\left[\left(\mathrm{eNd}_{1}, \mathrm{eNf}_{1}\right)\right.$, $\left.\left(\mathrm{eNd}_{2}, \mathrm{eNf}_{2}\right),\left(\mathrm{eNd}_{3}, \mathrm{eNf}_{3}\right),\left(\mathrm{eNd}_{4}, \mathrm{eNf}_{4}\right)\right]$ response envelopes. Two unload-reload paths and pinching behavior are defined with six parameters [(rDispP, rForceP, uForceP), (rDispN, rForceN, uForceN)], respectively, refer to the 
pinched ratio of the deformation at which reloading or unloading occurs to the historic deformation demand of each cycle. $\mathrm{rForceP}$ and $\mathrm{rForceN}$ individually indicate the pinched ratios of the forces corresponding to the historic deformation demand of each cycle under reloading and unloading. uForceP and uForceN represent the pinched ratios of strengths under reloading and unloading, respectively.

\section{Results and discussion}

\section{Damage observed}

The damage observed for the beam-column connection is shown in Fig. 13. Up to $R=1 / 30 \mathrm{rad}$, no appreciable damage was observed. At higher deformation demand, pullout of the tapered nut was observed for HTA400 and HTA500 (Fig. 13a). This was due to high tensile force demand, consequent contraction of the tapered nut and pullout. However, for HTA600-1, as the connection was stronger with higher moment capacity, the damage observed was bending inducing cracking of the column (Fig. 13b). The pushover testing was discontinued after the manifestation of this crack. The damages observed in the column-base connection are shown in Fig. 14. Figure 14 shows that the failure mode observed in the column-base connection is tensile failure (pullout).

\section{Hysteretic responses}

Hysteretic responses of HTA400, HTA500, and HTA600 connections are plotted in Fig. 15. All three results indeed showed pinching, as a result of the tapered nut pullout. All specimens showed a gradual strength degradation after maximum load capacity was reached. Furthermore, HTA600 showed higher capacity but reduced ductility. Furthermore, as shown in Fig. 13b, as the columns were cracked, the HTA600-1 test was discontinued around $150-\mathrm{kNm}$ moment (see Fig. 15c). Hysteretic responses of HCB4, HCB5, and HCB8 connections are plotted in Fig. 16. The column-base connection showed similar pinching response as the column-beam connection. Unlike the column-beam connection, all specimens showed a rapid strength degradation after maximum load capacity was reached.

To examine salient features of the connections (stiffness, strength, ductility, and energy dissipation capacity), first, the load-deformation curves of each test were obtained from envelope of the hysteretic curves. Figures 17 and 18 show the load deformation curves for beam-column and columnbase connections, respectively. Finally, the load-deformation curves were fitted with a bilinear curve, and the salient features were computed and summarized in Tables 1 and 2,

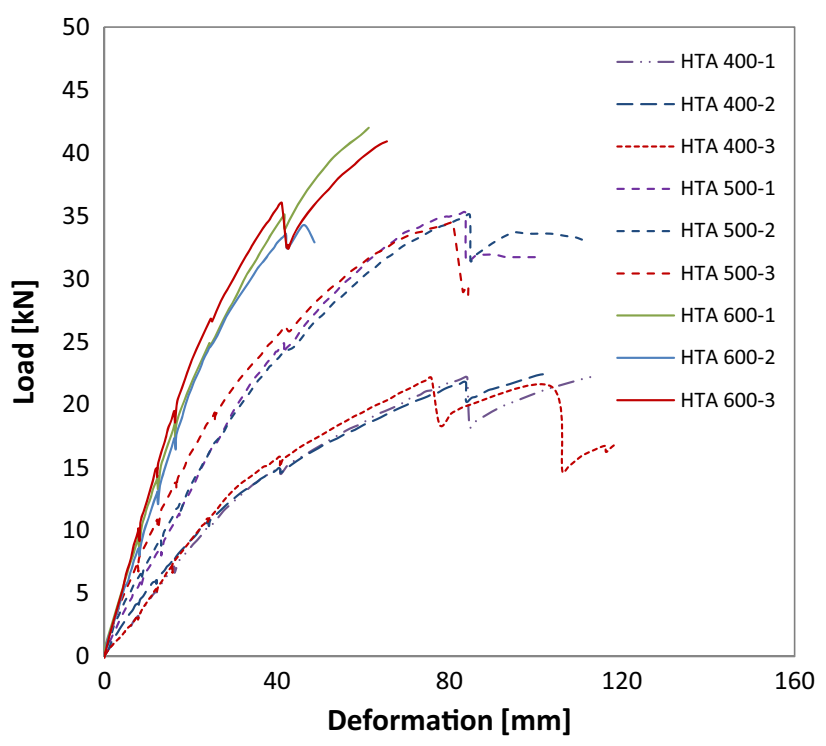

Fig. 17 Load-deformation envelope curves of beam-column connections

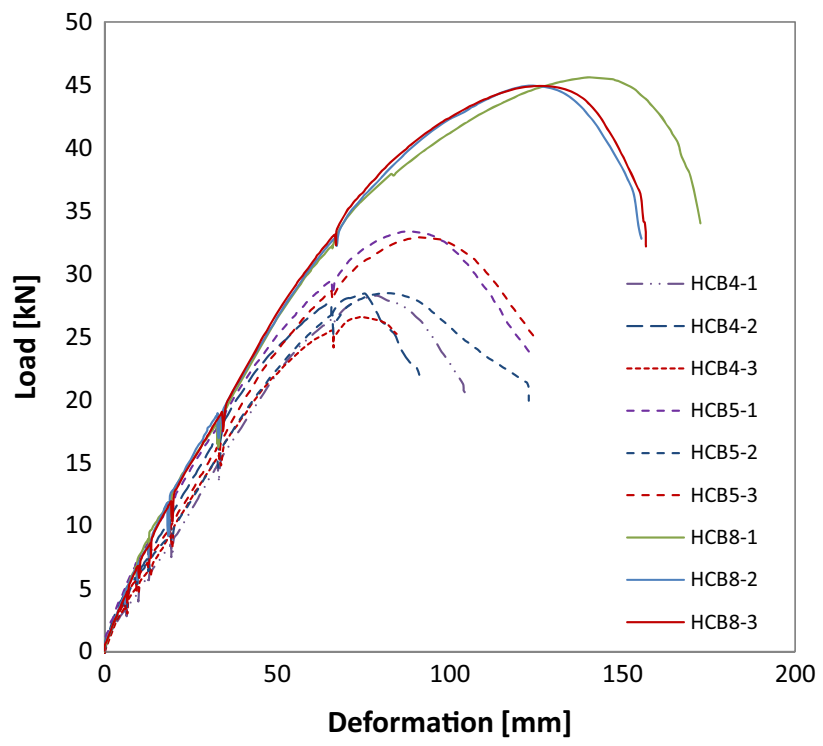

Fig. 18 Load-deformation envelope for semirigid column-base connection

respectively, for the beam-column and column-base connections. Each result is discussed further below.

Figure 17 shows that, overall, with beam depth and number of connections increasing, the overall stiffness and strength capacity of the systems increased. The stiffness, yield force, and ultimate force capacity, as expected, increased with increase in the beam depth (HTA600 > HTA500 > HTA400). It should be noted that both HTA500 and HTA600 have the same number of LSBs, and the difference was only the beam sizes. Both HTA600 and HTA500 showed higher energy dissipation and ductility capacity. Results of HTA500 and HTA600 are 
Table 1 Load deformation properties of semirigid column-base connection

\begin{tabular}{llclllll}
\hline Specimen & $P_{\max }(\mathrm{kN})$ & $\delta_{\text {Pmax }}(\mathrm{mm})$ & Stiffness K $(\mathrm{kN} / \mathrm{mm})$ & Energy & $P_{\mathrm{u}}(\mathrm{kN})$ & Ductility, $\mu=\delta_{\mathrm{u}} / \delta_{\mathrm{v}}$ & $D_{\mathrm{s}}=1 / \mathrm{sqrt}(2 \mu-1)$ \\
\hline HTA400-1 & 22.22 & 83.78 & 0.44 & 1758 & 19.68 & 2.37 & 0.52 \\
HTA400-2 & 22.42 & 101.67 & 0.43 & 1544 & 19.64 & 2.21 & 0.54 \\
HTA400-3 & 22.13 & 75.82 & 0.48 & 1594 & 19.46 & 2.38 & 0.52 \\
HTA500-1 & 35.24 & 83.68 & 0.63 & 2431 & 31.76 & 2.05 & 0.57 \\
HTA500-2 & 35.05 & 84.74 & 0.62 & 2748 & 32.13 & 2.19 & 0.54 \\
HT500-3 & 34.46 & 80.18 & 0.77 & 1970 & 30.39 & 2.16 & 0.55 \\
HTA600-1 & 42.00 & 61.28 & 1.10 & 1611 & 36.32 & 1.81 & 0.62 \\
HTA600-2 & 34.27 & 46.40 & 1.02 & 1058 & 31.73 & 1.58 & 0.68 \\
HTA600-3 & 40.92 & 65.49 & 1.21 & 1793 & 36.47 & 2.01 & 0.58 \\
\hline
\end{tabular}

Table 2 Load deformation properties of semirigid column-base connection

\begin{tabular}{llllllll}
\hline Specimen & $P_{\max }(\mathrm{kN})$ & $\delta_{\text {Pmax }}(\mathrm{mm})$ & Stiffness K $(\mathrm{kN} / \mathrm{mm})$ & Energy & $P_{\mathrm{u}}(\mathrm{kN})$ & Ductility, $\mu=\delta_{\mathrm{u}} / \delta_{\mathrm{v}}$ & $D_{\mathrm{s}}=1 / \mathrm{sqrt}(2 \mu-1)$ \\
\hline HCB4-1 & 28.27 & 79.12 & 0.41 & 1881 & 28.42 & 1.47 & 0.72 \\
HCB4-2 & 28.41 & 74.86 & 0.48 & 1692 & 26.94 & 1.71 & 0.64 \\
HCB4-3 & 26.58 & 74.56 & 0.45 & 1690 & 24.83 & 1.80 & 0.62 \\
HCB5-1 & 33.39 & 88.54 & 0.52 & 2702 & 31.29 & 1.99 & 0.58 \\
HCB5-2 & 28.46 & 81.08 & 0.43 & 2280 & 27.54 & 1.83 & 0.61 \\
HCB5-3 & 32.91 & 91.30 & 0.46 & 2746 & 31.35 & 1.84 & 0.61 \\
HCB8-1 & 45.60 & 140.61 & 0.49 & 5561 & 43.49 & 1.99 & 0.58 \\
HCB8-2 & 44.96 & 123.77 & 0.54 & 4771 & 41.84 & 1.98 & 0.58 \\
HCB8-3 & 44.94 & 125.38 & 0.53 & 4899 & 42.06 & 2.00 & 0.58 \\
\hline
\end{tabular}

Table 3 Parameters for the beam-column connection analytical model

\begin{tabular}{llll}
\hline Connection type & & & \\
\hline Parameters & HTA 400-1 & HTA 500-1 & HTA 600-1 \\
\hline$E_{\mathrm{s}}(\mathrm{MPa})$ & $205,939.65$ & $205,939.65$ & $205,939.65$ \\
$A_{\mathrm{s}}\left(\mathrm{mm}^{2}\right)$ & 153.86 & 153.86 & 153.86 \\
$E_{\mathrm{w}}(\mathrm{MPa})$ & 65,000 & 65,000 & 65,000 \\
$A_{\mathrm{w}}\left(\mathrm{mm}^{2}\right)$-beam & 3815 & 3815 & 3815 \\
$A_{\mathrm{w}}\left(\mathrm{mm}^{2}\right)$-column & 44,959 & 44,959 & 44,959 \\
$l(\mathrm{~mm})$-beam & 425.3 & 425.3 & 425.3 \\
$l(\mathrm{~mm})$-column & 214.3 & 214.3 & 214.3 \\
$f_{\mathrm{v}}\left(\mathrm{N} / \mathrm{mm}^{2}\right)$-beam & 6.5 & 6.5 & 6.5 \\
$\Gamma\left(\mathrm{N} / \mathrm{mm}^{3}\right)$-beam & 10.6 & 10.6 & 10.6 \\
$f_{\mathrm{v}}\left(\mathrm{N} / \mathrm{mm}^{2}\right)$-column & 6.2 & 6.2 & 6.2 \\
$\Gamma\left(\mathrm{N} / \mathrm{mm}^{3}\right)$-column & 9.24 & 9.24 & 9.24 \\
$P_{\text {max }}(\mathrm{kN})$-beam & 90.2 & 90.2 & 90.2 \\
$P_{\text {max }}(\mathrm{kN})$-column & 62.0 & 62.0 & 62.0 \\
$R(\mathrm{~mm})$ & 18 & 18 & 18 \\
$\mathrm{ks}(\mathrm{kN})$-beam & 145.5 & 145.5 & 145.5 \\
\hline
\end{tabular}

Table 4 Parameters for the column-base connection analytical model

\begin{tabular}{llll}
\hline & \multicolumn{3}{l}{ Connection type } \\
\cline { 2 - 4 } Parameters & HCB 4-1 & HCB 5-1 & HCB 8-1 \\
\hline$E_{\mathrm{s}}(\mathrm{MPa})$ & $205,939.65$ & $205,939.65$ & $205,939.65$ \\
$A_{\mathrm{s}}\left(\mathrm{mm}^{2}\right)$ & 153.86 & 153.86 & 153.86 \\
$E_{\mathrm{w}}(\mathrm{MPa})$ & 65,000 & 65,000 & 65,000 \\
$A_{\mathrm{w}}\left(\mathrm{mm}^{2}\right)$ & 3815 & 3815 & 3815 \\
$l(\mathrm{~mm})$-column & 500 & 500 & 500 \\
$f_{\mathrm{v}}\left(\mathrm{N} / \mathrm{mm}^{2}\right)$-column & 6.2 & 6.2 & 6.2 \\
$\Gamma\left(\mathrm{N} / \mathrm{mm}^{3}\right)$-column & 9.24 & 9.24 & 9.24 \\
$P_{\mathrm{max}}(\mathrm{kN})$-column & 93.7 & 93.7 & 93.7 \\
$R(\mathrm{~mm})$ & 18 & 18 & 18 \\
$\mathrm{ks}(\mathrm{kN})-$ column & 151.2 & 151.2 & 151.2 \\
\hline
\end{tabular}

particularly comparable, as the same number of LSBs was used. As the HTA600 beam failed prematurely, overall, the HTA500 showed better performance. It should be emphasized that, in capacity-based seismic design, the column 
Table 5 Analytical and experimental results of the rotation semirigidity and maximum moment for the beam-column connection

Table 6 Analytical and experimental results of the rotation semirigidity and maximum moment for the column-base connection

\begin{tabular}{lcclll}
\hline \multirow{2}{*}{ Beam depth $(\mathrm{mm})$} & \multicolumn{2}{l}{ Rotational semirigidity $(\mathrm{kNm} / \mathrm{rad})$} & & \multicolumn{2}{l}{ Maximum moment $(\mathrm{kNm})$} \\
\cline { 2 - 3 } & Experimental result & Analytical result & & Experimental result & Analytical result \\
\hline 400 & 4364 & 3592 & 75.0 & 71.3 \\
500 & 8904 & 7693 & 122 & 104 \\
600 & 16,301 & 12,884 & 153 & 141 \\
\hline
\end{tabular}

\begin{tabular}{llllll}
\hline Connection type & \multicolumn{2}{l}{ Rotational semirigidity $(\mathrm{kNm} / \mathrm{rad})$} & & \multicolumn{2}{l}{ Maximum moment $(\mathrm{kNm})$} \\
\cline { 2 - 3 } & Experimental result & Analytical result & & Experimental result & Analytical result \\
\hline HCB4 & 2672 & 3396 & 55.5 & 43.9 \\
HCB5 & 2828 & 3607 & 63.2 & 47.9 \\
HCB8 & 3546 & 5805 & & 90.4 & 63.0 \\
\hline
\end{tabular}

should be stronger than the beam. The HTA600 beam is stronger than the column, and as this did not meet the capacity-based design requirements, the damage in the column was observed.

Figure 18 shows that, overall, with increase in beam depth and number of connections, the maximum load capacity and corresponding deformation of the systems increased. However, the difference on the stiffness was not appreciable. This result is corroborated with the stiffness values presented in Table 2. From Table 2, it can be seen that the yield force, ultimate force capacity, and energy dissipation capacity has increased with increase in the beam depth and number of LSBs $(\mathrm{HCB} 4>\mathrm{HCB} 5>\mathrm{HCB} 8)$.

\section{Analytical model results}

The parameters needed for the analytical model were obtained from material test results reported in Nakatani et al. (2008). The material properties for the analytical model of the beamcolumn and column-base connections, respectively, are summarized in Tables 3 and 4. Following the analytical derivation shown in the previous section, the rotation semirigidity and maximum moments were computed, and the results are summarized in Tables 5 and 6, respectively. These results are also plotted in Figs. 19 and 20, respectively, for the beam-column and column-base connections.

From Table 5, it can be highlighted that the variation in the rotation semirigidity of the analytical and experimental results was $13-21 \%$, whereas the variation in the maximum moment between the analytical and experimental results was 5-18\%. The maximum moment and rotational semirigidity results plotted in Fig. 16 highlight that the proposed analytical model is in good agreement with the experimental results.

From Table 6 , the variation in the rotation semirigidity between the analytical and experimental results is 27-64\% overprediction, whereas the variation in the maximum moment between the analytical and experimental results is 21-30 \% underprediction. Results of the analytical model are plotted in Fig. 20. The results are not in good agreement with the experimental and numerical results. Possible reason for this error is, for HCB5 and HCB8, for example, as the connection is strong, with the high moment demand on the connection, the steel support was slightly bent during the test. This can increase the stiffness of the experimental test. In addition, the steel sleeve was slightly bent with higher cyclic demand. The analytical result shows higher semirigidity than what is shown from the experiment. This is the subject of further studies by the authors.

\section{Pinching4 hysteretic model results}

The Pinching4 hysteretic model was calibrated with the hysteretic curves shown in Figs. 15 and 16, and the 16 parameters are summarized in Table 7. The Pinching4 hysteretic curve results are plotted in Figs. 19 and 20 for the beam-column and column-base connections, respectively. It should be noted that the experimental reverse cyclic loads were only applied up to $R=1 / 30$ (rad) only. However, for the numerical model, the reverse cyclic loads were extended up to the maximum deformation obtained from the monotonic load. The Pinching4 hysteretic model results depicted in Figs. 19 and 20 show good agreement with the experimental hysteretic curves. Beyond $R=1$ / $30 \mathrm{rad}$, the load-deformation envelope closely matches the experimental envelop curves.

\section{Experimental and numerical results of the semirigid frame}

Performance of timber semirigid frame with LSBs connectors shown in Fig. 4 was investigated with initial cyclic and subsequent static pushover analysis. The schematic 


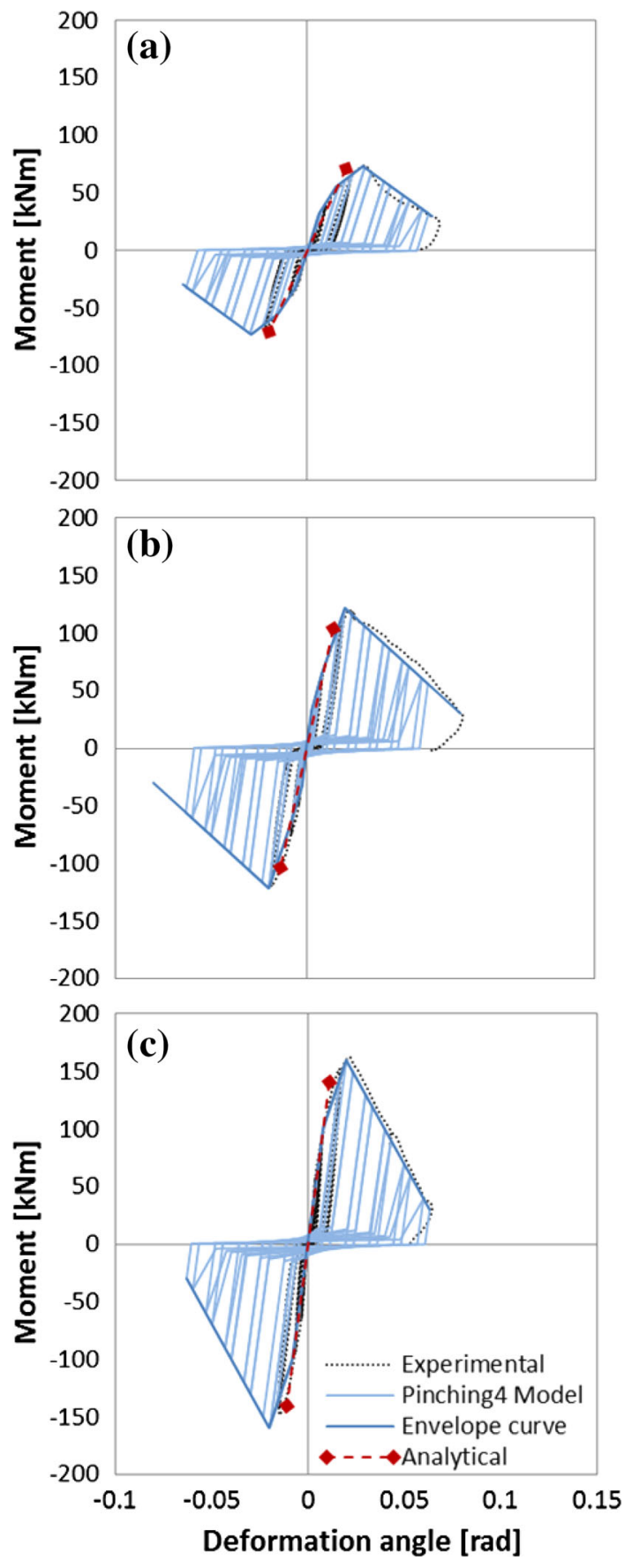

Fig. 19 Hysteric response of the three beam-column connections, a HTA400-1, b HTA500-1, and c HTA600-3

representation of Fig. 4 and instrumentation layout is shown in Fig. 21. The timber used was Japanese cedar, with Japanese Agricultural Standard grade of E65-F255 with Young's modulus and bending strength of 6500 and 25.5 MPa. The column height was $3140 \mathrm{~mm}$, and beam span was $6000 \mathrm{~mm}$. The column and beam dimensions were, respectively, $(300 \times 300 \mathrm{~mm})$ and $(240 \times 400$ / $500 \mathrm{~mm}$ ). Two beam depths (400 and $500 \mathrm{~mm}$ ) and three
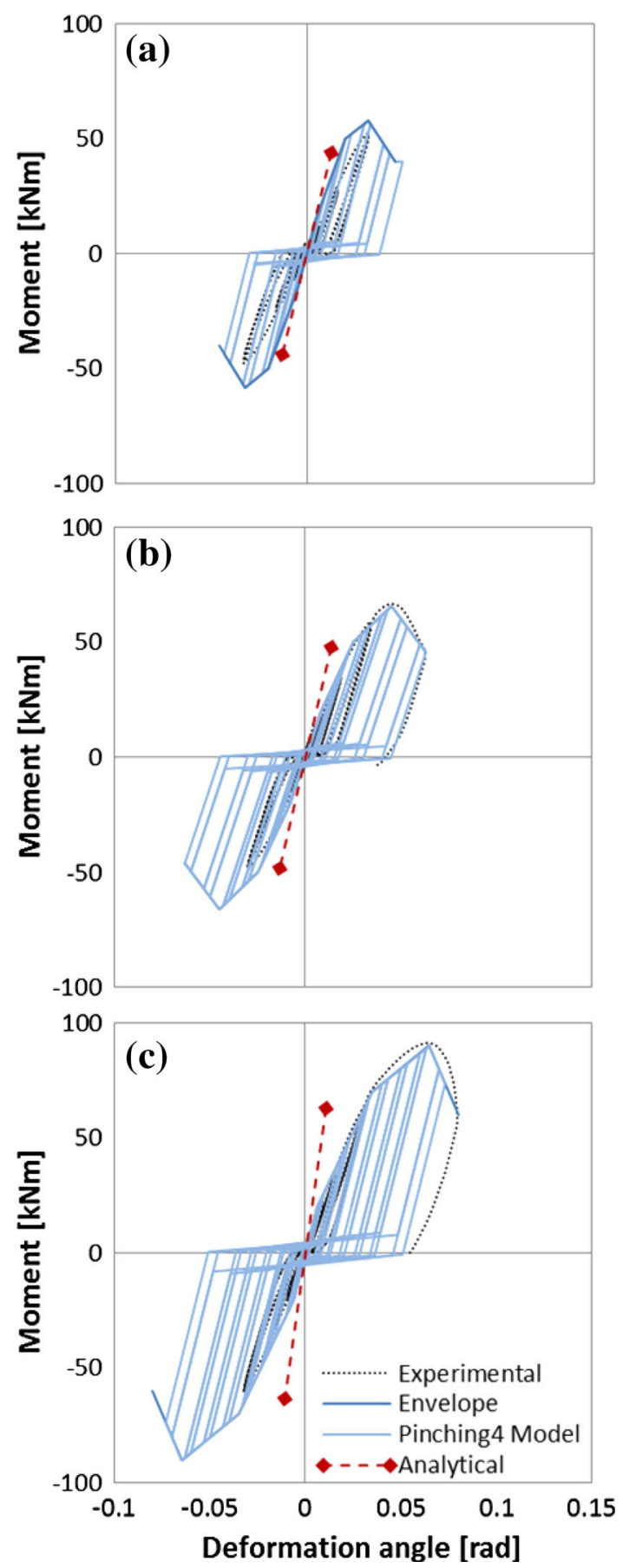

Fig. 20 Hysteric response of the three column-base connections, a $\mathrm{HCB} 4$, b HCB5, and c $\mathrm{HBC} 8$

replicate specimens were tested. A semirigid column-base connection and beam-column connection was used. The frame is tested with the cyclic response shown in Fig. 7 and subsequently pushed to collapse.

For the 400-mm beam depth, the observed failure modes were partial tensile failure of connection between LSB and plate in beam (Fig. 22a), pullout failure of LSB in column 
Table 7 Monotonic and hysteretic parameters estimation of Pinching4 model for the beam-column connection tests

\begin{tabular}{|c|c|c|c|c|c|c|c|}
\hline \multirow[t]{2}{*}{ Parameters } & & \multicolumn{6}{|c|}{ Connection type } \\
\hline & & HTA 400-1 & HTA 500-1 & HTA $600-1$ & HCB 4-1 & HCB 5-1 & HCB 8-1 \\
\hline \multicolumn{8}{|l|}{ Positive backbone } \\
\hline $\mathrm{ePf}_{1}(\mathrm{kN})$ & & 32 & 32 & 50 & 15 & 20 & 20 \\
\hline $\mathrm{ePf}_{2}(\mathrm{kN})$ & & 55 & 65 & 100 & 50 & 50 & 70 \\
\hline $\mathrm{ePf}_{3}(\mathrm{kN})$ & & 73 & 122 & 160 & 58 & 66 & 90 \\
\hline $\mathrm{ePf}_{4}(\mathrm{kN})$ & & 30 & 30 & 30 & 40 & 46 & 60 \\
\hline $\mathrm{ePd}_{1}(\mathrm{~mm})$ & & 0.006 & 0.0025 & 0.004 & 0.0045 & 0.008 & 0.006 \\
\hline $\mathrm{ePd}_{2}(\mathrm{~mm})$ & & 0.015 & 0.008 & 0.008 & 0.020 & 0.025 & 0.035 \\
\hline $\mathrm{ePd}_{3}(\mathrm{~mm})$ & & 0.029 & 0.020 & 0.020 & 0.032 & 0.045 & 0.065 \\
\hline $\mathrm{ePd}_{4}(\mathrm{~mm})$ & & 0.065 & 0.080 & 0.063 & 0.046 & 0.063 & 0.080 \\
\hline \multicolumn{8}{|l|}{ Negative backbone } \\
\hline $\mathrm{eNf}_{1}(\mathrm{kN})$ & & -32 & -32 & -50 & -15 & -20 & -20 \\
\hline $\mathrm{eNf}_{2}(\mathrm{kN})$ & & -55 & -65 & -100 & -50 & -50 & -70 \\
\hline $\mathrm{eNf}_{3}(\mathrm{kN})$ & & -73 & -122 & -160 & -58 & -66 & -90 \\
\hline $\mathrm{eNf}_{4}(\mathrm{kN})$ & & -30 & -30 & -30 & -40 & -46 & -60 \\
\hline $\mathrm{eNd}_{1}(\mathrm{~mm})$ & & -0.006 & -0.0025 & -0.004 & -0.0045 & -0.008 & -0.006 \\
\hline $\mathrm{eNd}_{2}(\mathrm{~mm})$ & & -0.015 & -0.008 & -0.008 & -0.020 & -0.025 & -0.035 \\
\hline $\mathrm{eNd}_{3}(\mathrm{~mm})$ & & -0.029 & -0.020 & -0.020 & -0.032 & -0.045 & -0.065 \\
\hline $\mathrm{eNd}_{4}(\mathrm{~mm})$ & & -0.065 & -0.080 & -0.063 & -0.046 & -0.063 & -0.080 \\
\hline \multicolumn{8}{|l|}{ Pinching } \\
\hline rDispP & & 0.8 & 0.8 & 0.8 & 0.8 & 0.8 & 0.8 \\
\hline fForceP & & 0.1 & 0.1 & 0.1 & 0.1 & 0.1 & 0.1 \\
\hline uForceP & & 0.01 & 0.01 & 0.01 & 0.01 & 0.01 & 0.01 \\
\hline rDispN & & 0.8 & 0.8 & 0.8 & 0.8 & 0.8 & 0.8 \\
\hline fForceN & & 0.1 & 0.1 & 0.1 & 0.1 & 0.1 & 0.1 \\
\hline uForceN & & 0.01 & 0.01 & 0.01 & 0.01 & 0.01 & 0.01 \\
\hline \multicolumn{8}{|c|}{ Unloading stiffness degradation } \\
\hline $\mathrm{gK}_{1}$ & & 0 & 0 & 0 & 0 & 0 & 0 \\
\hline $\mathrm{gK}_{2}$ & & 0 & 0 & 0 & 0 & 0 & 0 \\
\hline $\mathrm{gK}_{3}$ & & 0 & 0 & 0 & 0 & 0 & 0 \\
\hline $\mathrm{gK}_{4}$ & & 0 & 0 & 0 & 0 & 0 & 0 \\
\hline gKLim & & 0 & 0 & 0 & 0 & 0 & 0 \\
\hline \multicolumn{8}{|c|}{ Reloading stiffness degradation } \\
\hline $\mathrm{gD}_{1}$ & & 0 & 0 & 0 & 0 & 0 & 0 \\
\hline $\mathrm{gD}_{2}$ & & 0 & 0 & 0 & 0 & 0 & 0 \\
\hline $\mathrm{gD}_{3}$ & & 0 & 0 & 0 & 0 & 0 & 0 \\
\hline $\mathrm{gD}_{4}$ & & 0 & 0 & 0 & 0 & 0 & 0 \\
\hline gDLim & & 0 & 0 & 0 & 0 & 0 & 0 \\
\hline \multicolumn{8}{|l|}{ Strength degradation } \\
\hline $\mathrm{gF}_{1}$ & & 0 & 0 & 0 & 0 & 0 & 0 \\
\hline $\mathrm{gF}_{2}$ & & 0 & 0 & 0 & 0 & 0 & 0 \\
\hline $\mathrm{gF}_{3}$ & & 0 & 0 & 0 & 0 & 0 & 0 \\
\hline $\mathrm{gF}_{4}$ & & 0 & 0 & 0 & 0 & 0 & 0 \\
\hline gFLim & & 0 & 0 & 0 & 0 & 0 & 0 \\
\hline Energy degradation & $\mathrm{gE}$ & 1 & 1 & 1 & 1 & 1 & 1 \\
\hline Damage type & Energy & Energy & Energy & Energy & Energy & Energy & Energy \\
\hline
\end{tabular}




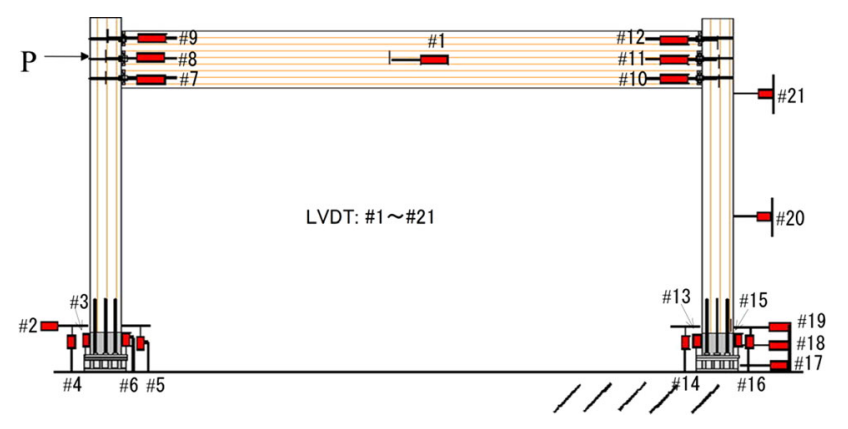

Fig. 21 Details of semirigid frame and instrumentation

(Fig. 22b), and partial tensile failure of connection between LSB and column-base joint (Fig. 22c). For the 500-mm beam depth, similar failure modes as shown in Fig. 22 were observed. In addition, for the 500-mm beam depth, the observed failure modes were shear failure at the column with subsequent splitting at the top of column (Fig. 23a) and bending failure at the column (Fig. 23b). The failures in the columns were a direct consequence of the 500-mm beam depth having a stronger column-beam connection and weaker column. This indeed reinforces the need to have strong column-weak beam seismic capacity design.
The pushover tests were performed for three replicate of each systems. The load-deformation results obtained from the pushover test are shown in Fig. 24a, b, for beam depth of 400 and $500 \mathrm{~mm}$, respectively. Figure 24 highlights that the three replicate frames showed consistent responses. The HR500 had higher maximum load carrying capacity than the HR400. The average loads were $120 \mathrm{kN}$ for HR400 and

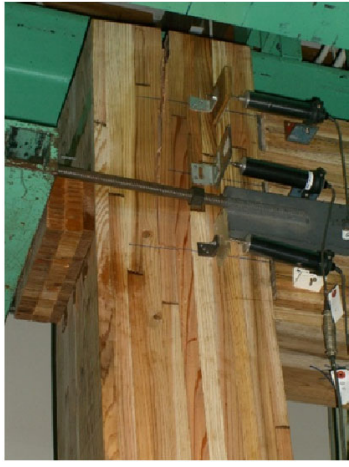

(a) Spilt at the top column

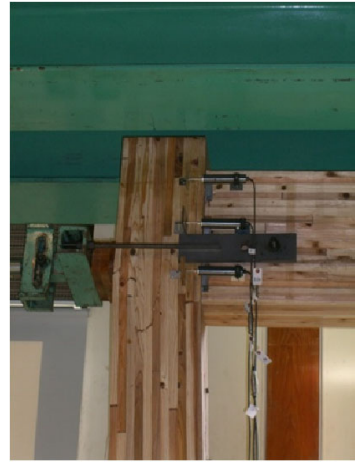

(b) Bending crack on the column
Fig. 23 Damage observed in the columns of the portal frame test
Fig. 22 Damage observed in the portal frame test

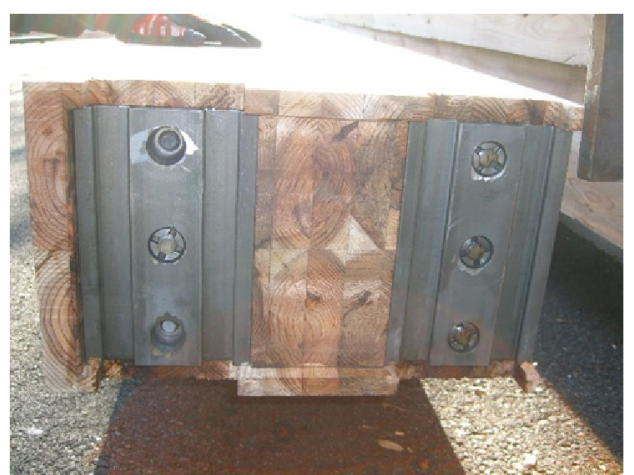

(a) Partial tensile failure of connection between LSB and plate in beam

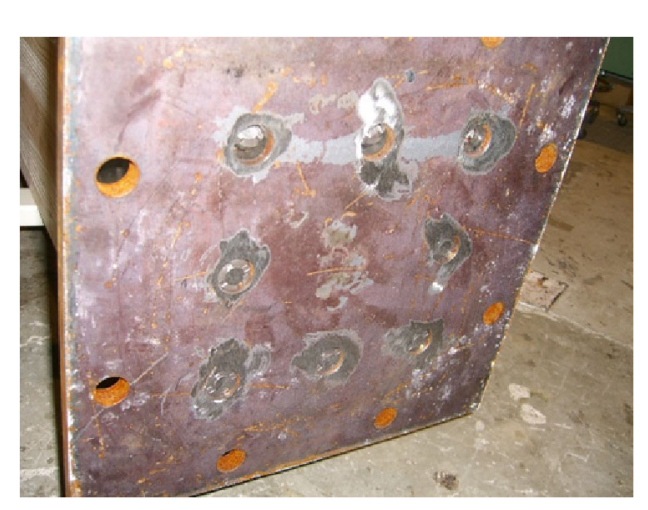

(c) Partial tensile failure of connection

between LSB and column base joint

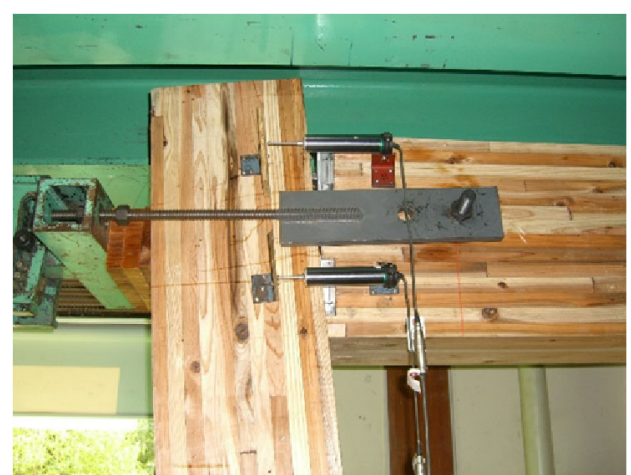

(b) Pullout failure of LSB in column 


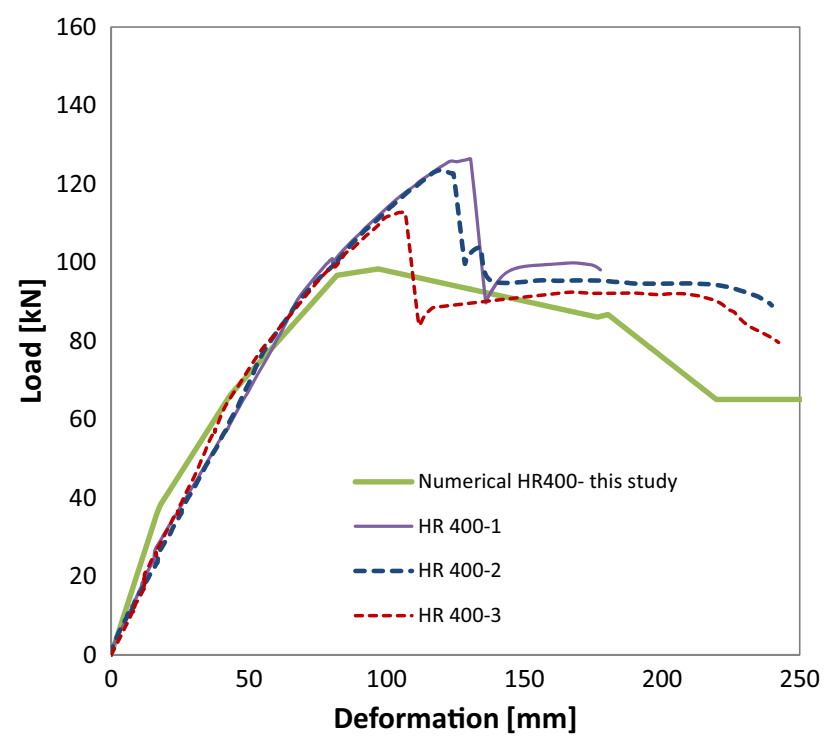

(a) HR400

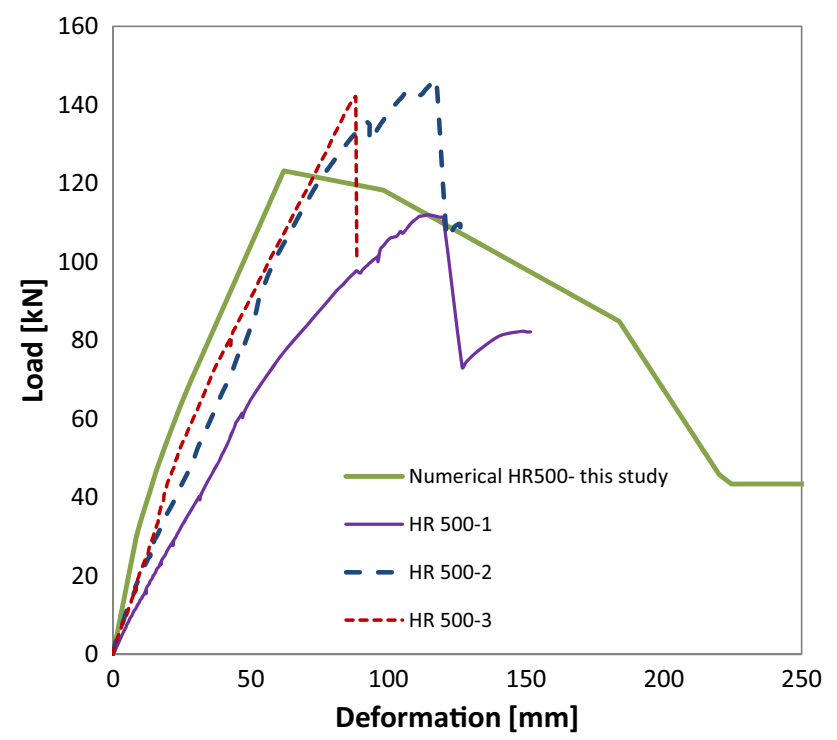

(b) HR500

Fig. 24 Analytical and experimental test load-deformation envelope for portal frame

$133 \mathrm{kN}$ for HR500. Once the system reached maximum load capacity, however, there was a big drop for both systems. After this drop, the HR400 portal frame continued to deform without loss of strength and had higher ductility. The HR500 portal frame, however, after the peak load, failed in a brittle manner without showing any ductility.

Schematic of the finite element model of the portal frame is depicted in Fig. 25. The frame is modeled in OpenSees using a lumped plasticity approach. The nonlinearity was limited within the connection, a zero-length spring model was used to model the connection, and the beam and columns were treated as linear element. The

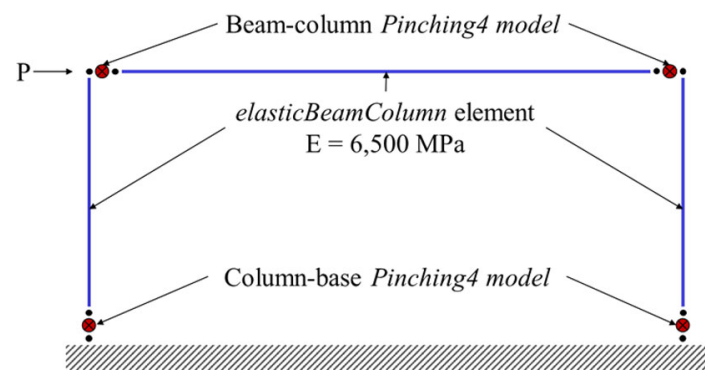

Fig. 25 Details of semirigid timber frame model in OpenSees

timber columns and beam were modeled in OpenSees as elasticBeamColumn element, with the corresponding area and moment of inertia computed from the sectional properties. The timber modulus of elasticity was $6500 \mathrm{MPa}$ (Japanese cedar, E65-F255). The plastic rotation was modeled with the Pinching4 hysteretic model calibrated from the connection tests. A static pushover analysis was carried out to a maximum deformation of $250 \mathrm{~mm}$. Result of the pushover analysis is plotted in Fig. 24. The numerical results, shown in Fig. 24, capture the overall load-deformation of experimental test results up to the maximum load. For the HR500, however, the brittle failure was not captured. As the brittle failure was in the column, the use of only lumped plasticity model with elastic column assumption did not capture this failure model. As well, in the derivation of the connection models, effects of axial forces in beams and columns were neglected in the numerical model of the portal frame. Indeed, the modeling can be further enhanced with the above formulation, but for the overall response analysis, this model can indeed be extended to model buildings with similar connection types.

\section{Conclusion}

Semirigid frame systems are prevalent in Japanese timber construction industry. To develop analytical prediction tools, however, reliability analytical and numerical models are needed. In this paper, a series of reverse cyclic and static pushover experimental tests were carried out for different sizes of beam-column (depths of 400, 500, and $600 \mathrm{~mm})$ and column-base (4, 5, 8 LSBs) connections. For all connections, both analytical and numerical models were developed. It should be noted that the testing cycles followed the Japanese standard loading criteria; however, instead of repeating the loading sequence three times, only one cycle was used. For this preliminary study of deriving analytical and numerical solutions, this simplification was sufficient, but further tests are required with the proper loading sequence. The following conclusions can be drawn. 
- For the beam-column connections, as expected, with increase in depth of the connection, the overall moment resistance and stiffness increased and ductility reduced.

- For the column-base connection, with increase in number of LSBs, the strength, stiffness, and ductility increased.

- The material model available in OpenSees, Pinching4 hysteretic model, was calibrated for connections. The numerical model shows good agreement with the experimental test results.

- The analytical model for the beam-column connection shows agreement with the maximum moment and stiffness. However, the analytical model for the column-base connection overpredicted the stiffness and underpredicted the strength.

Furthermore, utility of the numerical models was explored for a glulam timber portal frame structure with different beam sizes and connection types. The analytical model of the portal frame was developed in OpenSees. The following simplification was made in the analytical model of the portal frame:

- The effect of shear force was neglected in deriving the column-base connection models.

- As the brittle failure in the column was observed, the use of only lumped plasticity model with elastic column assumption did not capture this failure model.

- The effects of axial forces in beams and columns were neglected in the modeling of the portal frame.

Despite these limitations, however, there was good agreement with the experimental test results. The Pinching4 hysteretic model can be used in full-scale structural modeling of timber frames. The authors are carrying out further studies and calibration to improve the analytical and numerical models.

Acknowledgments The research was supported by the Grant-in-Aid for Scientific research of JSPS (17696048). The authors would like to express their sincere thanks to Professor Emeritus Kohei Komatsu of Kyoto University and Hara Tech Co. for their invaluable contribution.

Open Access This article is distributed under the terms of the Creative Commons Attribution 4.0 International License (http://creative commons.org/licenses/by/4.0/), which permits unrestricted use, distribution, and reproduction in any medium, provided you give appropriate credit to the original author(s) and the source, provide a link to the Creative Commons license, and indicate if changes were made.

\section{References}

Forestry Agency (2011). Annual Report on Forest and Forestry in Japan: Fiscal Year 2011. Ministry of Agriculture, Forestry and Fisheries, Japan, http://www.rinya.maff.go.jp/j/kikaku/hakusyo/ 23hakusyo/pdf/23_e.pdf. Accessed 17 Jun 2015

Foschi RO (2000) Modeling the hysteretic response of mechanical connections for wood structures. In: Proc, world conf. on timber engineering (WCTE): Whistler, Canada
Inoue M, Okibayshi S, Tanaka K, Yazu S, Goto Y (1999) Development and application of new type connecting system in timber structures: application to heavy timber structures. J Archit Build Sci 8:91-96 (in Japanese)

Komatsu K, Hara Y, Nanami Y, Ikki T (1999) Development of Lagscrewbolt as a connector for Glulam moment-resisting joints. In: Proceedings of Pacific Timber Engineering Conference, 14-18 March 1999, Rotorua, New Zealand, pp 2.349-2.354

Kouris LAS, Meireles H, Bento R, Kappos AJ (2014) Simple and complex modelling of timber-framed masonry walls in Pombalino buildings. Bull Earthq Eng. doi:10.1007/s10518-0149586-0

Lowes LN, Mitra N, Altoontash A (2004) A beam-column joint model for simulating the earthquake response of reinforced concrete frames. PEER Report 2003/10, Pacific Earthquake Engineering Research Center, February 2004

McKenna F, Fenves GL, Scott MH (2000) Open system for earthquake engineering simulation, University of California, Berkeley. http://opensees.berkely.edu. Accessed Jan 2015

Mori T, Nakatani M, Komatsu K (2009) Development on the structural performance of one directional timber frame using lagscrewbolts having an external thread. J Struct Eng B 55B:213-218 (in Japanese)

Nakatani M, Komatsu K (2005a) Expression mechanism of pull-out performance in Lagscrewbolted timber joints I. Effects of lead hole diameter, embedment depth, embedment directions and edge distance on the pull-out performance. Mokuzai Gakkaishi 51(2):125-130 (in Japanese)

Nakatani M, Komatsu K (2005b) Expression mechanism of pull-out performance in Lagscrewbolted timber joints II. Development of theory on pull-out properties Parallel to the grain. Mokuzai Gakkaishi 51(5):311-317 (in Japanese)

Nakatani M, Komatsu K (2006) Expression mechanism of pull-out performance in Lagscrewbolted timber joints III. Development of a theory of pull-out properties perpendicular to the grain. Mokuzai Gakkaishi 52(3):160-167 (in Japanese)

Nakatani M, Mori T, Komatsu K (2008) Study on the beam-column joint of timber frame structures using lagscrewbolts and special connectors. J Struct Constr Eng 73(626):599-606 (in Japanese)

Rahmanishamsi E, Soroushian S, Maragakisa M (2015) Cyclic shear behavior of gypsum board-to-steel stud screw connections in nonstructural walls. Earthquake Spectra, in press, http://dx.doi. org/10.1193/062714EQS091M. Accessed 29 Apr 2015

Rinaldin G, Amadio C, Fragiacomo M (2013) A component approach for the hysteretic behaviour of connections in cross-laminated wooden structures. J Earthq Eng Struct Dyn. doi:10.1002/eqe. 2310

Sato M, Isoda H, Sugaya Y (2007) Experimental study for timberbased semi-rigid frame with bolt and bond. J Archit Build Sci 13(26):539-544 (in Japanese)

Shen YL, Schneider J, Tesfamariam S, Stiemer SF, Mu Z (2013) Hysteresis behavior of bracket connection in cross-laminatedtimber shear walls. Constr Build Mater 48:980-991

Shojo N, Fujitani Y, Makishima Y, Nogomi H, Ohno Y, Ohashi Y (2004) Study on the beam-column joint of timber frame structures using drift pins. J Struct Constr Eng 578:91-97 (in Japanese)

Shojo N, Ohno Y, Fujitani Y, Ohashi Y (2005) Experimental study on the two story timber frame structure using drift pin joints (structures). J Archit Building Sci 22:185-188 (in Japanese)

Tlustochowicz G, Serrano E, Steiger R (2011) State-of-the-art review on timber connections with glued-in steel rods. Mater Struct 44(5):997-1020

Volkersen O (1938) Die Nietkraftverteilung in zugbeanspruchten Nietverbindungen mit konstanten Laschenquerschnitten. Luftfahrtforschung 15:41-47 